\title{
Involvement of Kallikrein-Related Peptidases in Normal and Pathologic Processes
}

\author{
Ana Carolina B. Stefanini, ${ }^{1,2}$ Bianca Rodrigues da Cunha,, \\ Tiago Henrique, ${ }^{1}$ and Eloiza H. Tajara ${ }^{1,2}$ \\ ${ }^{1}$ Department of Molecular Biology, School of Medicine of São José do Rio Preto, 15090-000 São José do Rio Preto, SP, Brazil \\ ${ }^{2}$ Department of Genetics and Evolutionary Biology, Institute of Biosciences, University of São Paulo, 05508-090 São Paulo, SP, Brazil
}

Correspondence should be addressed to Eloiza H. Tajara; tajara@famerp.br

Received 7 July 2015; Revised 16 October 2015; Accepted 29 October 2015

Academic Editor: Sunil Hwang

Copyright (C) 2015 Ana Carolina B. Stefanini et al. This is an open access article distributed under the Creative Commons Attribution License, which permits unrestricted use, distribution, and reproduction in any medium, provided the original work is properly cited.

\begin{abstract}
Human kallikrein-related peptidases (KLKs) are a subgroup of serine proteases that participate in proteolytic pathways and control protein levels in normal physiology as well as in several pathological conditions. Their complex network of stimulatory and inhibitory interactions may induce inflammatory and immune responses and contribute to the neoplastic phenotype through the regulation of several cellular processes, such as proliferation, survival, migration, and invasion. This family of proteases, which includes one of the most useful cancer biomarkers, kallikrein-related peptidase 3 or PSA, also has a protective effect against cancer promoting apoptosis or counteracting angiogenesis and cell proliferation. Therefore, they represent attractive therapeutic targets and may have important applications in clinical oncology. Despite being intensively studied, many gaps in our knowledge on several molecular aspects of KLK functions still exist. This review aims to summarize recent data on their involvement in different processes related to health and disease, in particular those directly or indirectly linked to the neoplastic process.
\end{abstract}

\section{Introduction}

Human kallikrein-related peptidases (KLKs) are a subgroup of serine proteases that have important roles in regulating normal physiological functions, such as immune response, skin desquamation, enamel formation, and semen liquefaction, and the corresponding pathological conditions. There is growing evidence in the literature supporting the view that KLKs are also implicated in tumorigenesis by activating proteolytic processes associated with the neoplastic phenotype. The potential mechanisms involved include the modulation of growth factor bioavailability and activation of hormone and protease-activated receptors (PARs) resulting in proliferative signaling pathways, the degradation of extracellular matrix, cleavage of junction proteins and induction of an epithelial-mesenchymal transition (EMT) phenotype leading to increased tumor cell migration and invasion, and the modulation of interactions between cancer cells and their microenvironment promoting angiogenesis and other protumorigenic processes (reviewed by [1-3]).

The potential of KLKs as cancer markers has been suggested for several members of this protease family [2, 46], particularly for kallikrein-related peptidase 3 or prostatespecific antigen (PSA) [7]. PSA is well accepted for assessing recurrence risk in patients with prostate cancer, but its predictive power for diagnosis has been questioned, since several factors other than malignancy may be associated with its high levels in serum, such as preanalytical variables, benign diseases, and drugs $[8,9]$. Biomarker panels combining PSA and other promising markers, including members of the KLK family, are expected to improve prostate cancer screening and reduce unnecessary treatments, a strategy that may also be used for detection and monitoring of other malignancies and nonmalignant diseases.

In this paper, we review the current knowledge about the evolution and functions of human kallikrein-related 
peptidases, their substrates, and their role in health and disease, particularly in the context of cancer.

\section{The Human Degradome}

Protein synthesis is essential for living, metabolically active cells, but its counterpart, protein degradation, is no less important. Proteolytic mechanisms driven by proteases maintain appropriate protein levels and recognize and degrade the misfolded or mislocalized ones. In addition to acting in nonspecific catabolism, proteases are involved in selective cleavages and activations, modulating proteinprotein interactions and contributing to cell signaling both as catalytic units and as multicatalytic complexes. Due to their broad-spectrum actions, proteases play critical roles in regulating normal biological processes, including DNA replication and transcription, cell proliferation, differentiation, and apoptosis. When altered, they may facilitate the development of pathological conditions such as inflammatory and degenerative disorders (reviewed by [10]). The importance of these hydrolytic enzymes is reflected by the number of genes already identified in several mammalian species, with more than 500 in human and primates and even more in rodents [11-14].

The complete set of human proteases-named the human degradome-is distributed in aspartic-, threonine-, cysteine-, serine-, and metalloprotease classes according to the chemical group involved in their catalytic activity [15, 16], and the latter three are the most populated classes [10]. Their substrate cleavage patterns may be specific for a single peptide, as in the case of proteases involved in signaling pathways, or common for a broad range of peptides, which is well exemplified by digestive enzymes [17]. Otherwise, inactive proteases or pseudoproteases bind to their cognate substrate without cleaving them, thus exerting a regulatory function [18].

Detailed information on proteases in prokaryotes and eukaryotes, protease families, pseudogenes, the sequences derived from endogenous retroviruses, 3D structures, substrates, and proteolytic events has been accumulated in different databases such as MEROPS [19] and Degradome [20].

\section{The Serine Protease Group}

Approximately one-third of proteolytic enzymes are serine proteases, usually endopeptidases. These enzymes use the serine residue present in their active site as a nucleophile to attack the peptide bond of the substrate [21]. In humans, many serine proteases are involved in extra- and intracellular processes mainly related to food digestion, blood coagulation, and immunity (reviewed by $[1,22]$ ). Although these processes are essential for the purposes of catabolism or selective cleavages required for cell signaling, serine protease activity (as well as that of other proteases) is potentially devastating, and several cellular mechanisms were selected to modulate and keep them within limits. For example, they are stored as inactive zymogens or inside granules and can access the substrates only through controlled actions. In addition, serpins, a superfamily of serine protease inhibitors, antagonize their activities in many metabolic pathways, arresting the proteases into an irreversible complex (reviewed by [1]).

Although tightly controlled, several serine proteases have been associated with human diseases. For example, high granzyme levels (granule-secreted enzymes found in cytotoxic T cells and natural killer cells) have been observed in chronic inflammatory diseases such as rheumatoid arthritis [23], asthma [24], diabetes [25], atherosclerosis [26], and chronic obstructive pulmonary [27] and cardiovascular diseases [28]. They have also been implicated in susceptibility to skin tearing and disorganized collagen as observed in chronic wounds and aged/sun-damaged skin (reviewed by [29]). The role of granzymes in these conditions resides in their ability to cleave many substrates, inducing apoptosis through caspasedependent and caspase-independent pathways [30]. Their potential to create or destroy autoimmune epitopes [31] and be improperly regulated in chronic wounds or released nonspecifically from immune cell into extracellular spaces also contributes to chronic inflammation or extracellular matrix disorganization $[27,32]$.

Increased levels of neutrophil proteases such as elastase, cathepsin G, and myeloblastin have also been correlated with the severity of cystic fibrosis and chronic obstructive pulmonary disease [33]. Similarly, tryptase and chymase, two serine proteases stored in mast cell granules, take part in the pathophysiology of asthma [34], psoriasis [35], atherothrombosis [36], and fibrotic [37] and inflammatory kidney diseases [38].

With respect to cancer, several serine proteases have been linked to tumor development and progression by activating proteolytic processes that are associated with the neoplastic phenotype (reviewed by [1]). Specifically, a family of serine proteases expressed and secreted in many tissues participates in complex networks of cell signaling pathways that are related to cancer [4-7]. One of the most useful cancer biomarkers in clinical medicine is kallikrein-related peptidase 3 or PSA, which is a member of this family (reviewed by [7]), and there is evidence that other KLKs are also deregulated in cancer and other diseases [4,39-147] as summarized in Table 1 .

\section{The Human Kallikreins}

Human kallikreins, initially detected at high levels in pancreas, kallikreas in Greek, include plasma and tissue serine proteases, which are two categories that differ in molecular weight, substrate specificity, and gene structure. The unique plasma kallikrein (PKK) is a glycoprotein encoded by the $K L K B 1$ gene on chromosome region $4 \mathrm{q} 35$ and is predominantly synthesized in the liver as an inactive precursor. After activation by the coagulation factor XII, PKK cleaves high molecular weight kininogen to release bradykinin, a mediator of blood coagulation, inflammation, blood pressure, and thrombosis risk [148].

4.1. Kallikrein-Related Peptidases at DNA Level: Genomic Organization and Evolutionary Aspects. The 15 tissue kallikreins or kallikrein-related peptidases (KLKs) are encoded by genes that are tightly clustered in an approximately 
TABLE 1: Kallikrein-related peptidases. Gene expression pattern, SNPs, and promoter methylation related to cancer and other diseases. CSF = cerebrospinal fluid.

\begin{tabular}{|c|c|c|c|c|}
\hline Disease & Kallikrein & Factor & Observation & Reference \\
\hline \multirow[b]{2}{*}{ Alzheimer's disease } & KLKs 6 (CSF), 10 & Increased expression & & \multirow[b]{2}{*}[39-42]{} \\
\hline & $\begin{array}{l}\text { KLKs } 6 \text { (brain, } \\
\text { blood), } 7\end{array}$ & Decreased expression & & \\
\hline Amelogenesis imperfecta & KLK4 & Mutation & Disease-causing mutation & [43-45] \\
\hline \multirow{2}{*}{ Aneurism } & KLK6 & Decreased expression & $\begin{array}{l}\text { Suggestion of unfavorable } \\
\text { prognosis }\end{array}$ & \multirow[b]{2}{*}[46,47]{} \\
\hline & $K L K 8$ & SNP & $\begin{array}{c}\text { Suggestion of unfavorable } \\
\text { prognosis }\end{array}$ & \\
\hline Asthma & $K L K 3$ & SNP & & {$[48]$} \\
\hline Atopic dermatitis & KLK5 & Decreased expression & & {$[49,50]$} \\
\hline Bipolar disease & $K L K 8$ & SNP & $\begin{array}{l}\text { Suggestion of unfavorable } \\
\text { prognosis }\end{array}$ & {$[51]$} \\
\hline \multirow{2}{*}{ Coronary artery disease } & KLK1 & SNP & Controversial prognosis & \multirow{2}{*}[52,53]{} \\
\hline & $K L K 1$ & Increased expression & Predictor of disease & \\
\hline \multicolumn{5}{|l|}{ Kidney disease } \\
\hline Lupus nephritis & KLK1 & SNP & Disease-associated SNP & \multirow{3}{*}[54-56]{} \\
\hline Acute kidney injury & $K L K 1$ & SNP & $\begin{array}{c}\text { Suggestion of unfavorable } \\
\text { prognosis }\end{array}$ & \\
\hline Diabetic nephropathy & $K L K 1$ & Increased expression & Tubular inflammation & \\
\hline Multiple sclerosis & KLK6 & Increased expression & Advanced disease & [57-59] \\
\hline Dementia with Lewy bodies & KLK6 & Decreased expression & Suggestion of diagnostic marker & {$[60]$} \\
\hline Other neurodegenerative diseases & $\begin{array}{l}\text { KLKs } 1,5,6,7 \\
\text { and } 9\end{array}$ & Increased expression & $\begin{array}{l}\text { Suggestion of disease-associated } \\
\text { marker }\end{array}$ & {$[61-63]$} \\
\hline Other skin diseases & $\begin{array}{c}K L K s \\
5-8,10-13 \text {, and } \\
15\end{array}$ & Increased expression & $\begin{array}{l}\text { Suggestion of unfavorable } \\
\text { prognosis }\end{array}$ & [64-73] \\
\hline Netherton syndrome & KLK5 & Increased expression & $\begin{array}{c}\text { Suggestion of unfavorable } \\
\text { prognosis }\end{array}$ & \\
\hline \multirow[t]{2}{*}{ Psoriasis } & $K L K 8$ & Increased expression & $\begin{array}{l}\text { Suggestion of unfavorable } \\
\text { prognosis }\end{array}$ & \multirow[t]{2}{*}[74,75]{} \\
\hline & $\begin{array}{l}\text { KLKs } 6,8,10 \\
\quad \text { and } 13\end{array}$ & Increased expression & Severity of skin lesions & \\
\hline Parkinson's disease & KLK6 & Increased expression & Disease-associated marker & {$[76]$} \\
\hline Sjogren disease & KLK11 & Increased expression & $\begin{array}{c}\text { Suggestion of disease-associated } \\
\text { marker }\end{array}$ & {$[77]$} \\
\hline \multirow{7}{*}{ Breast cancer } & KLKs 2, 4 & SNP & Breast cancer risk & \multirow{7}{*}[4,47,78-83]{} \\
\hline & $K L K 3$ & SNP & $\begin{array}{l}\text { Association with less } \\
\text { aggressiveness }\end{array}$ & \\
\hline & $\begin{array}{c}\text { KLKs 5, 10, and } \\
14\end{array}$ & Increased expression & Potential diagnostic biomarkers & \\
\hline & $\begin{array}{c}\text { KLKs } 6,12 \\
\text { variant 3, and } 15\end{array}$ & Increased expression & Suggestion of favorable prognosis & \\
\hline & $\begin{array}{c}\text { KLKs 3, 8, and } \\
12\end{array}$ & Decreased expression & Suggestion of favorable prognosis & \\
\hline & KLKs 5, 7 & Increased expression & $\begin{array}{l}\text { Suggestion of unfavorable } \\
\text { prognosis }\end{array}$ & \\
\hline & $K L K 10$ & Methylation & Suggestion of favorable prognosis & \\
\hline Cervix cancer & KLK7 & Increased expression & Controversial prognosis & {$[84,85]$} \\
\hline Colorectal cancer & $\begin{array}{c}K L K s 4,6,7 \text {, and } \\
10\end{array}$ & Increased expression & $\begin{array}{l}\text { Suggestion of unfavorable } \\
\text { prognosis }\end{array}$ & {$[86-90]$} \\
\hline
\end{tabular}


TABle 1: Continued.

\begin{tabular}{|c|c|c|c|c|}
\hline Disease & Kallikrein & Factor & Observation & Reference \\
\hline \multirow{3}{*}{ Gastric cancer } & $\begin{array}{c}\text { KLKs } 6,7 \text {, and } \\
10\end{array}$ & Increased expression & $\begin{array}{l}\text { Suggestion of unfavorable } \\
\text { prognosis }\end{array}$ & \multirow{3}{*}[90-95]{} \\
\hline & KLK13 & Increased expression & Suggestion of favorable prognosis & \\
\hline & KLK11 & Decreased expression & $\begin{array}{c}\text { Suggestion of unfavorable } \\
\text { prognosis }\end{array}$ & \\
\hline \multirow{2}{*}{ Head and neck cancer } & KLK10 & Methylation & $\begin{array}{l}\text { Suggestion of unfavorable } \\
\text { prognosis }\end{array}$ & \multirow{2}{*}{ [96-99] } \\
\hline & KLKs 4-8, 10 & Increased expression & $\begin{array}{l}\text { Suggestion of unfavorable } \\
\text { prognosis }\end{array}$ & \\
\hline Intracranial tumor & KLKs 6-8 & Increased expression & Controversial prognosis & {$[100,101]$} \\
\hline \multirow{4}{*}{ Lung cancer } & KLK10 & Methylation & & \multirow{4}{*}[102-106]{} \\
\hline & KLKs 5-7 & Increased expression & $\begin{array}{l}\text { Suggestion of unfavorable } \\
\text { prognosis }\end{array}$ & \\
\hline & $\begin{array}{c}\text { KLKs } 11,13 \text {, and } \\
14\end{array}$ & Increased expression & Diagnostic marker & \\
\hline & KLKs 8, 12 & Decreased expression & $\begin{array}{l}\text { Suggestion of unfavorable } \\
\text { prognosis }\end{array}$ & \\
\hline \multirow[t]{2}{*}{ Melanoma } & $\begin{array}{c}\text { KLKs } 6,8 \text {, and } \\
13\end{array}$ & Increased expression & & \multirow[t]{2}{*}[107,108]{} \\
\hline & KLK7 & Increased expression & Suggestion of favorable prognosis & \\
\hline \multirow{5}{*}{ Ovarian cancer } & $K L K s 4,6$ & Increased expression & Advanced stage & \multirow{5}{*}{$\begin{array}{l}{[47,78,109-} \\
125]\end{array}$} \\
\hline & $\begin{array}{l}\text { KLKs } 8-10, \\
11,13, \text { and } 14\end{array}$ & Increased expression & Suggestion of favorable prognosis & \\
\hline & KLKs 5, 7 & Increased expression & $\begin{array}{l}\text { Suggestion of unfavorable } \\
\text { prognosis }\end{array}$ & \\
\hline & $K L K 10, K L K P 1$ & SNP & & \\
\hline & KLKs 3, 15 & SNP & $\begin{array}{l}\text { Suggestion of unfavorable } \\
\text { prognosis }\end{array}$ & \\
\hline Pancreatic cancer & KLK7 & Increased expression & Controversial prognosis & {$[126]$} \\
\hline \multirow{8}{*}{ Prostate cancer } & $K L K 3$ & Increased expression & $\begin{array}{l}\text { Disease monitoring and } \\
\text { recurrent prediction }\end{array}$ & \multirow{8}{*}{$\begin{array}{l}{[47,78,127-} \\
147]\end{array}$} \\
\hline & $\begin{array}{c}\text { KLKs } 1,2,4 \text {, and } \\
15\end{array}$ & Increased expression & & \\
\hline & KLKP1 & Decreased expression & & \\
\hline & $K L K 7$ & Increased expression & Controversial prognosis & \\
\hline & KLK11 & Decreased expression & $\begin{array}{c}\text { Suggestion of unfavorable } \\
\text { prognosis }\end{array}$ & \\
\hline & $\begin{array}{c}K L K s 2,3,4 \text {, and } \\
10\end{array}$ & SNP & $\begin{array}{c}\text { Suggestion of unfavorable } \\
\text { prognosis }\end{array}$ & \\
\hline & KLK12 & SNP & Cancer predisposition & \\
\hline & $\begin{array}{c}\text { KLKs } 4,14 \text {, and } \\
15\end{array}$ & SNP & $\begin{array}{c}\text { Suggestion of unfavorable } \\
\text { prognosis }\end{array}$ & \\
\hline
\end{tabular}

$300 \mathrm{~kb}$ sequence of the $19 \mathrm{q} 13.33-13.41$ chromosome region, all containing 5 coding exons with comparable lengths and sequence homology $[149,150]$. A pseudogene (KLKP1) has also been assigned to this region [151], as well as multiple repetitive elements such as ALU, Tigger2, MER8, and MSR1 [152]. The large contiguous human KLK gene cluster is limited by the ACPT (testicular acid phosphatase) gene and the Siglec (sialic acid-binding immunoglobulin-like lectin) family of genes at centromeric and telomeric positions, respectively, and other less characterized genes (SNORD88C, C19orf48, MGC45922, and CTU1) (Figure 1).

The colocation and sequence conservation in a wide variety of species make this human tissue serine proteinase family a very interesting target for evolutionary studies [153]. The phylogenetic analysis of KLKs performed by the Maximum Likelihood method [154], using the transcript isoforms of $15 K L K$ genes, the pseudogene-1 (KLKP1) sequence, and the PRSS1 (trypsin 1) transcript sequence as an external group, 


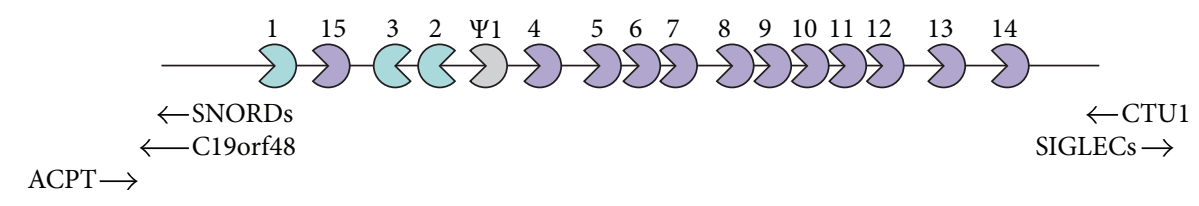

(a)

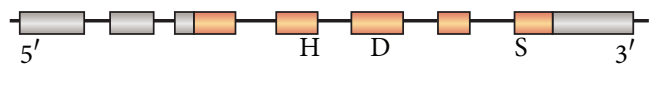

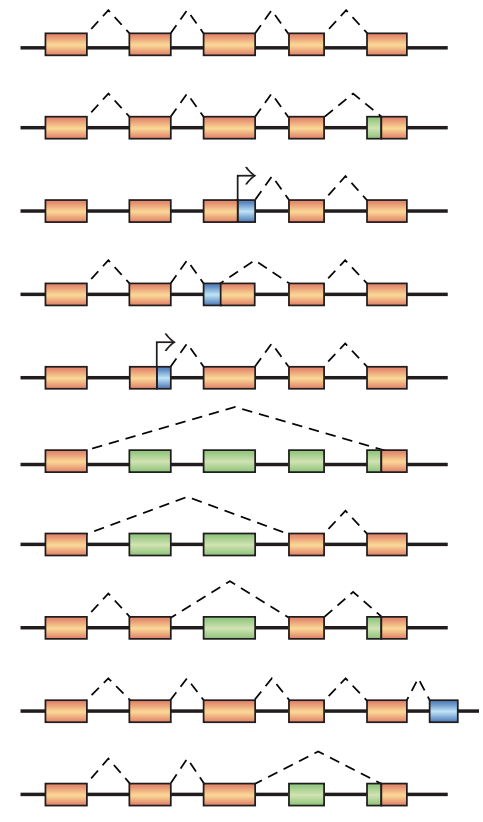

(b)

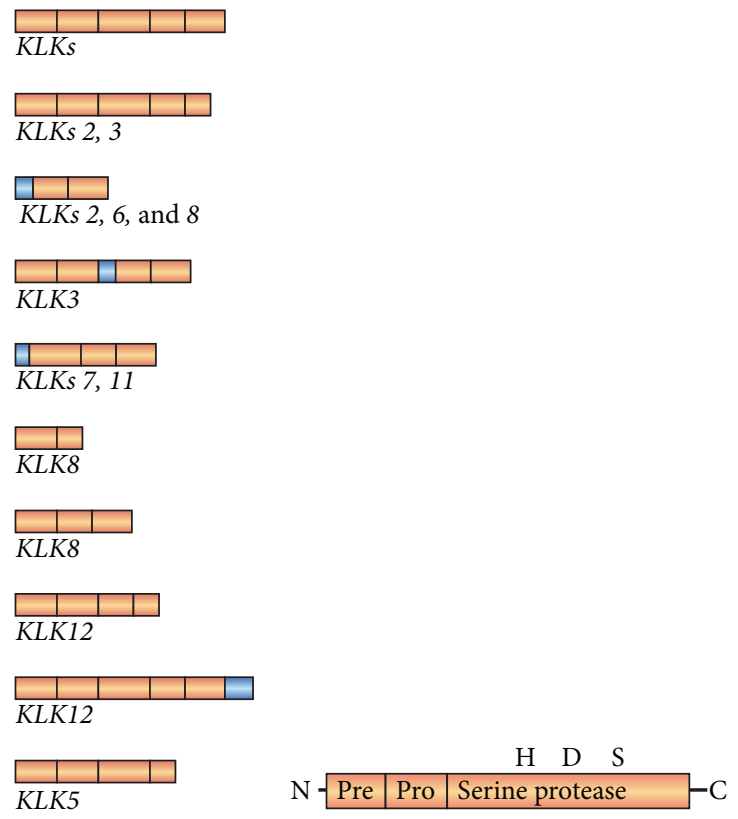

(c)

FIGURE 1: KLK gene cluster and schematic representation of the human $K L K$ gene and protein structure. (a) KLK gene cluster on the 19q13.3313.41 chromosome region including the pseudogene $K L K P 1$ and the transcriptional direction from centromere to telomere, except for KLK2 and $K L K 3$, which have the opposite transcriptional direction. The classic KLK genes (KLKs 1-3) are turquoise, KLK4-KLK15 are medium purple, and the $\Psi$ KLK1 processed pseudogene is silver; the arrowheads represent the neighboring genes: $A C P T$ (testicular acid phosphatase) and the Siglec (sialic acid-binding immunoglobulin-like lectin) gene family as well as other less characterized genes (SNORDs, C19orf48, and CTU1). (b) The human KLK gene consists of 5 coding exons (orange boxes represent coding exons; silver boxes represent noncoding exons) and their 4 intervening introns. The positions of the catalytic residues are highly conserved with the histidine (H), aspartic acid (D) 3 , and serine (S) codons on coding exons 2,3, and 5, respectively. Most KLK genes demonstrate alternative splicing, which generates several transcript variants. Alternative $3^{\prime}$ splice sites or skipped exons (shown in green) result in short variants of KLKs $2,3,5,8$, and 12 genes. Alternative $5^{\prime}$ splice sites or start sites (shown in blue) also generate short variants of KLKs 2, 3, 6, 7, 8, and 11 genes. Utilization of the alternative exon 6 generates a long transcript encoding a variant of KLK12 gene (shown in blue). (c) KLK proteins are single-chain proteases that are synthesized as preproenzymes and are proteolytically processed to pro-KLKs and secreted after removal of the terminal signal peptide (Pre). The KLK sequence also includes a propeptide (Pro) that maintains the inactive state of the enzyme, as well as a serine protease domain.

reveals five major branches: (a) the classic KLKs (KLKs 1-3), (b) KLKs 4, 5, 7, and 14 and KLKP1, (c) KLKs 9 and 11 , (d) KLKs 8,10 , and 15 , and (e) KLKs 12 and 13 , and a separate branch with KLK6. The tree (Figure 2) is similar in several aspects to other phylogenetic analyses of this cluster $[150,153,155-$ 157] but also includes the isoforms and reinforces the idea that all KLK genes evolved from a single gene by successive tandem duplications and genomic rearrangements facilitated by repetitive elements.

The high similarity between $K L K 2$ and $K L K 3$ sequences and the highest support value also suggest that they might have formed by duplication later in evolution. The data grouping $K L K 4 / K L K 5$ and $K L K 9 / K L K 11$ also corroborate previous studies $[153,156]$. The isolated position of KLK6 in this phylogenetic tree, unlike the findings of other authors, may explain the apparent distance of the remaining family members in respect to normal and pathological functions.

4.2. Kallikrein-Related Peptidases at RNA Level: Transcriptional Regulation Mechanisms. Kallikrein-related peptidase expression is regulated at transcriptional, translational, and posttranslational levels. At the transcriptional level, several response elements (REs) have been identified in the KLK promoters such as an estrogen-related receptor $\gamma(\mathrm{ERR} \gamma)$ response element [158], a GATA binding motif in KLK1 [159], and functional retinoic acid response elements (RAREs) in 


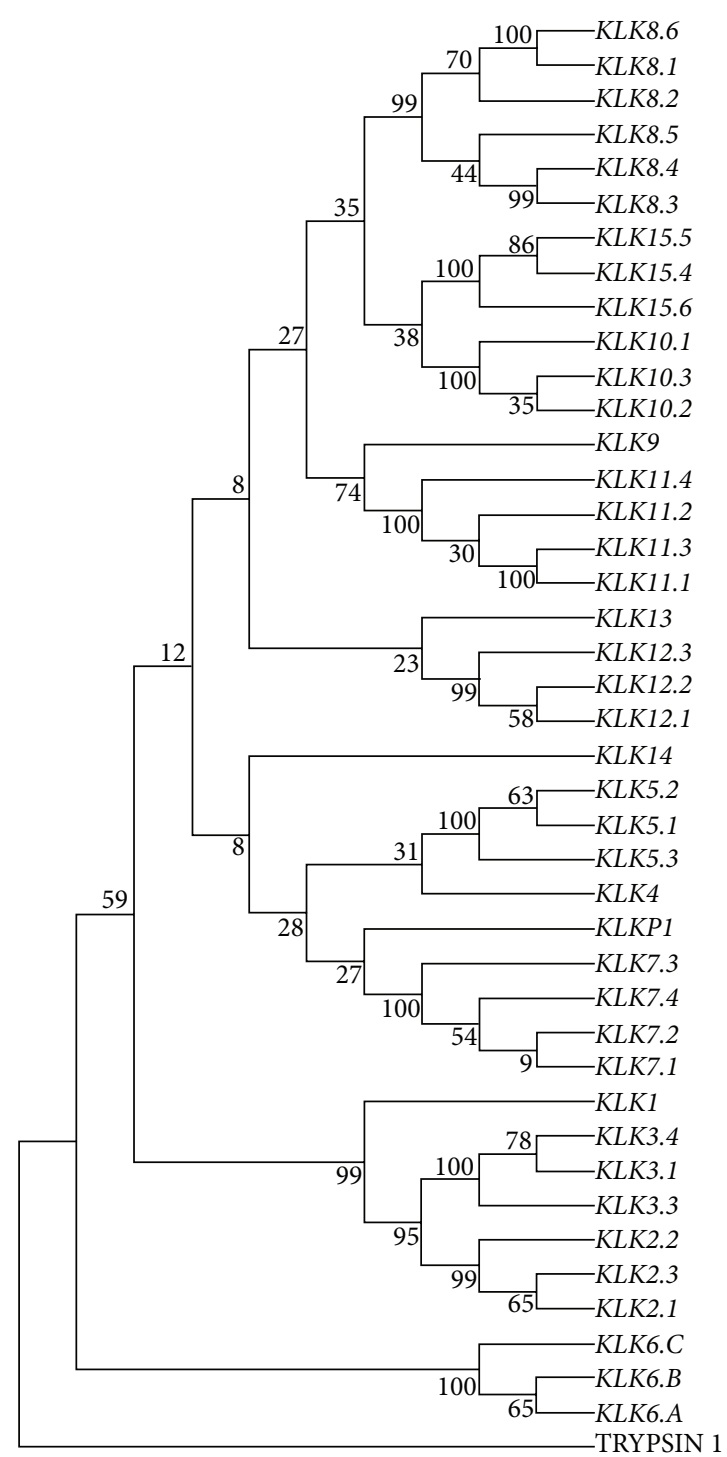

FIGURE 2: Phylogenetic relationships within the human tissue KLK gene family in humans. Phylogenetic analysis was performed using the MEGA5 [205] and Maximum Likelihood methods based on the GTR model (General Time Reversible) [154] with Gamma distribution. The bootstrap method was used (with 1000 data set replicates) to investigate node robustness [206]. The phylogenetic tree includes $15 \mathrm{KLK}$ transcripts, the pseudogene-1 (KLKP1) sequence, and the trypsin 1 gene sequence (PRSS1) $[155,156]$. The sequences were obtained from the NCBI Reference Sequence (RefSeq) database (http://www.ncbi.nlm.nih.gov/). Numbers indicate the percentage of 1000 bootstrap replicates at each node in the consensus. Bootstrap value $\leq 95$.

$K L K 10$ [160]. Due to the importance of KLK3 expression in prostate cancer, a number of REs have already been described for its promoter, including Sp1/Sp3 [161] and WT1 transcription factor-binding sites [162], a putative p53 RE [163], an $\mathrm{XBE}$ (X-factor-binding element that binds specifically to the NF-kappaB p65 subunit) in the AREc (androgen response element enhancer core) [164], and androgen-responsive elements (AREs), the last of which were also present in the KLK2 promoter (reviewed by $[127,165]$ ).

$K L K$ gene expression can also be regulated by epigenetic mechanisms, including histone modifications such as DNA methylation as well as microRNAs (reviewed by [166]), which can affect normal cell physiology and facilitate tumorigenesis if altered. In fact, aberrant promoter methylation leading to
KLK10 downregulation has been described in acute lymphoblastic leukemia [167] as well as in breast [168], gastric [91], and prostate cancer [169]. Similarly, abnormal histone acetylation at $K L K 2$ and $K L K 3$ sequences and deregulated expression of miRNAs targeting KLK genes have also been reported in kidney, prostate, and breast cancer cell lines (reviewed by [166]).

In addition to epigenetic events, polymorphisms in regulatory sequences can potentially alter RNA transcription rates and protein levels, as was observed for the homozygous $G$ base substitution (rs266882) in the androgen response element (ARE-1) of the KLK3 promoter [170] and for polymorphic alleles in the $5^{\prime}$-flanking region of the $K L K 1$ gene [171]. $K L K$ gene activity is likewise affected by polymorphisms in 
Tissue kallikreins

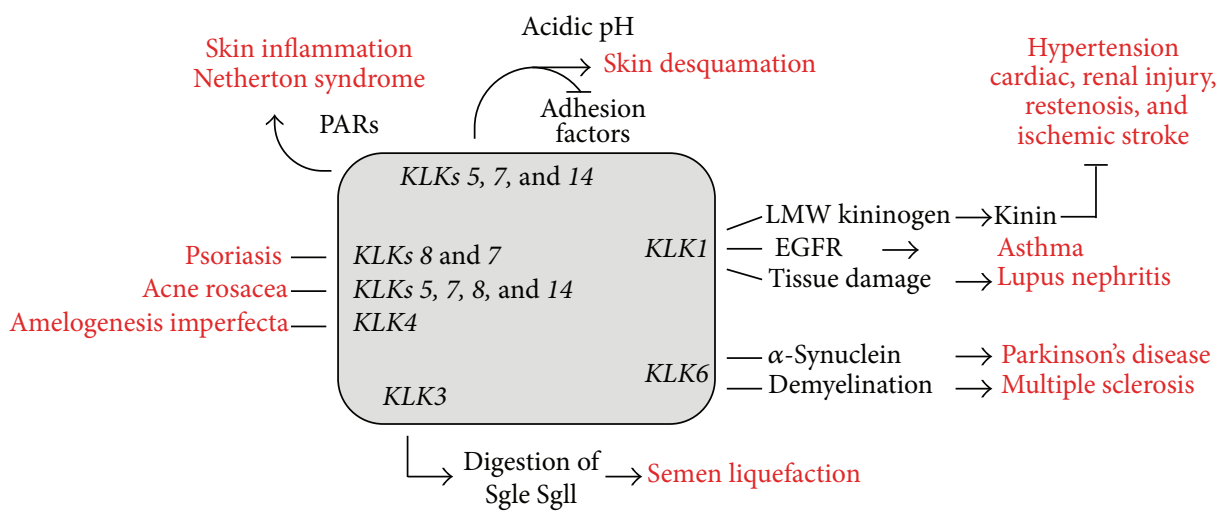

Plasma kallikreins

$$
\mathrm{PK} \longrightarrow \begin{aligned}
& \text { High MW } \\
& \text { kininogen }
\end{aligned} \text { Bradykinin } \rightarrow \begin{aligned}
& \text { Blood coagulation } \\
& \text { Blood pressure } \\
& \text { Inflammation }
\end{aligned}
$$

FIGURE 3: Schematic representation of KLK functions related to physiological and pathological conditions. KLKs are involved in several normal processes including blood pressure, coagulation, semen liquefaction, and skin desquamation and can also protect against cardiac injury and ischemia. These proteases may also participate in skin inflammation, neurodegeneration, and autoimmune diseases.

the coding region or in the $3^{\prime}$-UTR and downstream sequences of the KLK1,KLK2,KLK3, and KLK7 genes (reviewed by [47]).

According to the NCBI Reference Sequence Database (accessed in November 20, 2014), with the exceptions of KLK1, KLK4, KLK9, KLK13, and KLK14, human KLK genes have multiple isoforms. The alternative transcripts apparently are species specific [155], and a number of them are cancer specific (reviewed by [172]), which supports the idea that they are constantly evolving. The diversity of these isoforms, especially those with no peptidase catalytic motifs, may indicate a type of activity control, for example, by competing for the same substrates or performing different tissue-specific functions [155].

4.3. Kallikrein-Related Peptidases at Protein Level. The KLKs are proteins of 230 amino acids and 28 to $33 \mathrm{kDa}$, although some small isoforms reach only $3 \mathrm{kDa}$. Their standard tertiary structure consists of two juxtaposed six-stranded antiparallel $\beta$-barrels and two $\alpha$-helices with the active site between the barrels $[173,174]$. They are synthesized as preproenzymes, which are proteolytically processed to pro-KLKs and secreted after removal of the terminal signal peptide. Their ability to release kinins was initially viewed as the definition of a true kallikrein. However, besides plasma kallikrein, only KLK1 has the ability to cleave kininogen (in this case, low molecular weight kininogen) to release kinin. The tissue kallikrein-kinin system can protect against cardiac injury and ischemia/reperfusion-induced cardiomyocyte apoptosis as well as against oxidative stress-induced renal cell apoptosis via stimulation of kinin B2 receptor-Akt [175]. Otherwise, this system appears to be involved in the development of lupus nephritis by increasing local tissue damage triggered by autoimmune inflammation [176] (Figure 3).
As mentioned above, KLK promoters have several hormone response elements, and their expression can be regulated by steroid hormones [177]. Therefore, KLK levels in different tissues are dependent not only on the presence of specific transcriptional and translational regulators, but also on proteolytic mechanisms, as previously referred to in the degradome section. Shaw and Diamandis [178] detected distinct expression profiles for several kallikrein-related peptidases: KLK1 was highly expressed in the pancreas and salivary gland, KLKs 2, 3 (also observed in seminal plasma), and 11 were highly expressed in the prostate, KLK5 was expressed in the skin, KLK6 was expressed in the brain, KLK9 was expressed in the heart, and KLK12 was expressed in several anatomical sites. KLKs 4, 8, 14, and 15 exhibited a more homogeneous profile or were not detected in various tissues. Komatsu et al. [179] analyzed the skin stratum corneum and identified the presence of many KLKs (KLKs 5-8, 10, 11, 13, and 14). Generally, expression patterns are compatible with their origins-duplicate genes have similar expression patterns in the same tissues, and coexpression patterns are compatible with their physiological functions [153].

\section{Kallikrein-Related Peptidases and Their Relationship to Health and Disease}

5.1. Normal Physiological Processes and Nonmalignant Diseases. Similar to what has been observed for other proteases, several regulatory mechanisms protect tissues from harmful proteolysis by KLKs. In addition to controlled proenzyme activation and endogenous inhibitors (such as $\alpha_{2}$-macroglobulin and serpins), there are also inactivating cleavages and allosteric regulation (reviewed by [165]). Regulatory steps may be performed by other proteases including members of the KLK family, which are supported by their 
coexpression in the same tissue. For example, a KLK cascade including KLK2, KLK14, and probably other KLKs activates pro-KLK3 to generate the mature proteinase that directly cleaves the semenogelins SgI and SgII resulting in seminal clot liquefaction and spermatozoa release [180]. Recently, Yoon et al. [181] observed that MMP-20, which is usually expressed only in dental enamel, processes the prosequence of nine different KLKs and may be a nonspecific activator of the $K L K$ family in pathological conditions.

Another proteolytic cascade has been described for the skin desquamation process in which KLK5 may be autoactivated or activated by KLK14 at neutral $\mathrm{pH}$ and then process KLK7, regulating skin desquamation. This cascade may start by KLK6 autoactivation following the cleavage of KLK11, which in turn activates KLK14. Although not completely understood, skin desquamation also depends on other proteases, including cathepsins, aspartic proteases, urokinase, plasmin, and the inflammatory metalloproteinases. Because KLK regulation is critical for proper desquamation, various endogenous inhibitors participate as attenuators of their activities, mainly LEKTI (serine protease inhibitor Kazaltype 5), a protein encoded by the SPINK5 gene. Other factors such as an acidic environment and UV irradiation (and resulting inflammation) may inhibit LEKTI, also contributing to increased KLK expression and enhanced desquamation [64]. The lack of LEKTI expression in Netherton syndrome, a rare genetic skin disease characterized by congenital ichthyosis and severe allergic manifestations, indeed results in increased proteolytic activities of KLK5 and KLK7, which trigger an inflammatory process by activating proteaseactivated receptor-2 (PAR-2) and stimulating cytokine production [70] (Figure 3).

KLK deregulation is also observed in several other pathological conditions, of which neurodegenerative disorders are good examples (Figure 3). Alzheimer's disease (AD) and Parkinson's disease (PD) are the most prevalent human neurodegenerative disorders. Both are caused by the aggregation of proteins: $\mathrm{AD}$ is characterized by extracellular deposits of amyloid $\beta(\mathrm{A} \beta)$ and intraneuronal aggregates of tau protein in specific brain regions, and PD is characterized by intracellular neuronal deposits (Lewy bodies and neurites) formed by insoluble $\alpha$-synuclein [182, 183].

There is convincing evidence from the literature on Alzheimer's disease that KLK6, the most abundant kallikreinrelated peptidase in the central nervous system, cleaves the amyloid precursor protein (APP), a transmembrane glycoprotein from which $\mathrm{A} \beta$ derives. The proteolytic activity of KLK6 against APP and substrates in the extracellular matrix and perineuronal net places this peptidase as a potential component of AD pathogenesis. KLK6 expression is reduced in brain tissues, as well as in cerebrospinal fluid of $A D$ patients $[42,184,185]$, but the mechanisms behind these findings and their functional consequences are not yet known. Actually, other enzymes ( $\alpha-, \beta-$, and $\gamma$-secretases) cleave APP in different sites and generate several fragments; some of them are aggregation-prone [183]. KLKs may, for example, promote a bias toward synthesis of these toxic fragments by $\beta$ - and $\gamma$ secretases.
Besides KLK6, the kallikrein-related peptidases 7 and 10 show decreased and increased levels, respectively, in cerebrospinal fluid of AD patients [39]. Recently, Shropshire and collaborators observed that KLK7 is able to cleave the core of $\mathrm{A} \beta$ in vitro, inhibiting $\mathrm{A} \beta$ aggregation and reducing neuronal toxicity [186]. This result may open new opportunities towards treatments for AD.

Several studies on Parkinson's disease have implicated KLK6 in the degradation of intracellular $\alpha$-synuclein [187]. Recent data suggested that secreted $\alpha$-synuclein is also involved in the development of PD by affecting neuronal cell viability [188] and activating inflammatory response [189]. Although still controversial with respect to the intracellular type, KLK6 inefficiency in $\alpha$-synuclein degradation seems to contribute to $\mathrm{PD}$ pathogenesis, probably due to an altered trafficking of KLK6 [187, 190] or to the resistance of certain forms of $\alpha$-synuclein to KLK6-proteolysis [76, 191].

Multiple sclerosis (MS) is another example of neurodegenerative disorder in which KLK6 levels are altered. In MS patients, KLK6 is abundantly expressed and cleaves myelin proteins, resulting in demyelination and oligodendrogliopathy [192].

As may be noted from AD, PD, and MS data, KLK6 seems to be important for the neuronal homeostasis and survival. However, other kallikrein-related peptidases are probably involved in these processes, as can be deduced from the data on overexpression of KLK1 in epilepsy [193] and on the ability of a set of KLKs (KLK1, KLKs 5-7, and KLK9) to promote neural injury [62].

5.2. Malignant Diseases. As evidenced by the literature, particularly in prostate cancer, KLKs participate in proteolytic pathways that contribute to the neoplastic process (Figure 4). With respect to tumor growth, KLK1 facilitates EGFR and ERK1/2 cascade activation, which is involved in cell proliferation [194]. Similarly, KLK1, KLK2, and KLK3 can regulate tumor growth through IGF-binding protein (IGFBP) degradation, thereby allowing the release of the insulin-like growth factors (IGFs) and proliferative signals. However, a negative regulatory role for KLK3 in cancer has also been suggested because this protease can activate latent transforming growth factor- $\beta$ (TGF $\beta$ ), a known suppressor of growth and promoter of apoptosis [2].

Recent data have demonstrated that kallikrein-related peptidase 4 and its substrate, promyelocytic leukemia zinc finger protein (PLZF), modulate androgen receptor (AR) and mTOR signaling in prostate cells to regulate cell survival. In fact, KLK4 negatively regulates PLZF, thus preventing its binding and inhibition by AR, which keeps mTORC1 signaling active and ensures cell survival [195].

During neoplastic progression, different KLKs can regulate new vessel formation, which are essential to provide oxygen and nutrients to proliferating cancerous cells. KLKs 1 and 4 stimulate angiogenesis by cleaving kininogen to kinin or activating prometalloproteinases 2 and 9 to their active forms, thereby potentiating extracellular matrix hydrolysis and enabling endothelial cell migration and neovascularization [196-198]. Other kallikrein-related peptidases (KLKs 2 and 4) can stimulate the urokinase plasminogen activator 


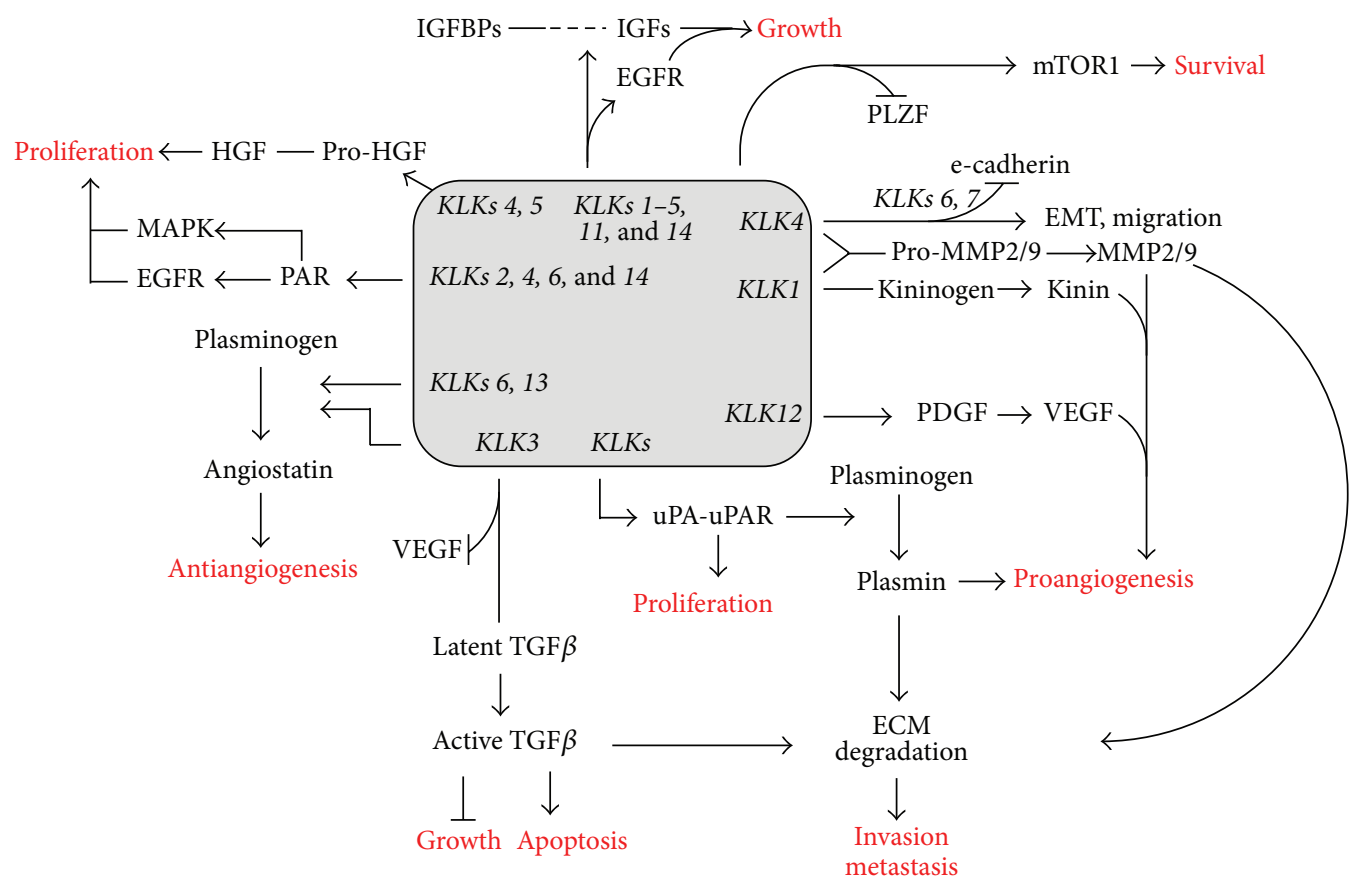

FIGURE 4: Kallikrein-related peptidases and cancer. KLKs participate in proteolytic pathways that contribute to the neoplastic process by facilitating cell proliferation via growth factors and modulating cell survival through mTOR signaling. They can also regulate angiogenesis, cell migration and invasion by angiogenic vascular endothelial growth factor (VEGF) secretion, metalloproteinase activation, extracellular matrix (ECM) degradation, and epithelial-mesenchymal transition (EMT) induction. However, KLKs also have a protective effect against cancer, promoting apoptosis or inhibiting angiogenesis and cell proliferation.

(uPA)/uPA receptor system, which also leads to metalloproteinase activation and extracellular matrix degradation [2]. KLK12 may then promote angiogenesis by the conversion of the membrane-bound platelet-derived growth factor $\mathrm{B}$ (PDGF-B) precursor into a soluble form that modulates secretion of the angiogenic vascular endothelial growth factor A (VEGF-A) [199]. Some KLKs, such as KLKs 3, 6, and 13, have the opposite action by blocking VEGF and/or fibroblast growth factor 2 (FGF2) or generating angiostatin-like fragments from plasminogen, which are potent inhibitors of angiogenesis in vitro [2].

Tumors have an increased acidic microenvironment resulting from accelerated glycolysis and lactate accumulation and thus low $\mathrm{pH}$ in the extracellular space [200]. Because an acidic environment may block the kallikrein inhibitor LEKTI, contributing to increased KLK expression and loss of cellular adhesion in skin desquamation, it is reasonable to consider a similar mechanism during neoplastic dissemination [201]. In fact, the metastatic process is associated with a transition from tightly connected cells to cells with increased motility, namely, the epithelial-mesenchymal transition, where KLKs play important roles. For example, KLKs activate latent $\operatorname{TGF} \beta$, which induces EMT, and are associated with the loss of E-cadherin in tumor cells and thus with decreased cell-cell adhesion [202]. They also trigger extracellular matrix degradation via prometalloprotease activation and hence promote tissue invasion [2].

These examples demonstrate how important kallikreinrelated peptidases are in tumor development and progression.
The biological processes in which they participate are related to diseases other than cancer but are directly connected with cancer pathways, including cell proliferation, adhesion, inflammation, and apoptosis.

\section{Therapeutic Relevance of KLKs}

As discussed in previous sections, KLKs have been associated with different pathologic processes, from skin diseases to neurodegenerative disorders and cancer. The progress in our knowledge on all members of this protein family, functions, $3 \mathrm{D}$ structures, substrates, and physiological roles, has provided opportunities to develop new therapeutic approaches for different disorders.

KLKs are targeted by several types of inhibitors, including small-molecule inhibitors, antibody-, protein-, and peptidebased inhibitors, KLK-activated prodrugs, interfering RNAs, and immunotherapeutic vaccines (reviewed by [3]). PROSTVAC, for example, is a prostate cancer vaccine consisting of a KLK3 recombinant vector that contains transgenes for three T-cell costimulatory molecules (TRICOM). This vaccine has demonstrated success in inhibiting, with few side effects, cell proliferation and tumor growth and in improving overall survival [203].

Prodrugs activated by KLKs are another strategy that has been investigated. For instance, KLK3-activated peptides have the ability to target the prostate since most KLK3 is expressed in the gland whereas circulating KLK3 is normally inactivated in plasma by endogenous inhibitors [204]. This 
drug has overcome the challenge of specificity, although similar successful results are not always achieved. The reasons for that include the fact that the active sites of members of KLK family are conserved, which hampers drug design. The resolution of 3D structure of KLKs should help in this regard. However, KLKs also have overlapping and even opposing actions, which certainly depend on the physiologic, tissue, and disease context [203].

\section{Conclusions}

The KLK network is impressive. Its intricate signaling pathways and protein interactions strongly show that this group of proteases contributes to normal and pathological metabolisms. However, despite being intensively studied, there are many gaps in our knowledge on the molecular aspects of the KLK family. For example, there is no doubt that KLK expression deregulation participates in the development of neurodegenerative disorders. But what exactly is its role? Would it be a primary and direct one, promoting erroneously protein degradation, which results in pathogenic fragments? Or would it be one that implies cooperating with specific secretases and other enzymes to generate toxic deposits?

In cancer, it is not clear whether KLKs alterations are driver mutations or deleterious passenger mutations. The fact that similar sets of KLKs are associated with different tumor types and facilitate proliferation, migration, and other cancer hallmarks aligns with driver mutations. Differently, antiproliferative effects of KLKs and similar regulatory factors for different members of this family may argue in favor of random passenger mutations. However, both statements are not mutually exclusive and may occur simultaneously or sequentially. In fact, the idea of sequential occurrence is interesting: considering the complexity of human proteolytic system, it is reasonable to assume that the expression of specific KLKs may counteract the under- or overexpression of other KLKs or enzymes or even that those KLKs are activated, one after the other, to neutralize the expression of a driver mutation, but without success. The analysis of KLK panels in large sets of samples from diverse stages of the disease, including premalignant phases, will probably help to reveal how the expression profile evolves during the course of the disease.

Many questions are still unanswered and the scenario is therefore incomplete. Many more data are necessary to improve our understanding on the function, substrates, and role of KLKs in health and disease in order to distinguish in each case whether they are heroes, villains, or supporting actors.

\section{Conflict of Interests}

The authors declare that they have no conflict of interests.

\section{Acknowledgments}

The authors thank the Fundação de Amparo à Pesquisa do Estado de São Paulo (FAPESP) (Grant no. FAPESP 10/511680); Coordenação de Aperfeiçoamento de Pessoal de Nível
Superior (CAPES); and Conselho Nacional de Pesquisas (CNPq) (Grant no. CNPq 306216/2010-8) for financial support and fellowships. They are also grateful to Mauro Golin for artwork preparation and to GENCAPO (Head and Neck Genome Project, http://www.gencapo.famerp.br/) team for the valuable discussions that motivated the present study.

\section{References}

[1] K. M. Heutinck, I. J. M. ten Berge, C. E. Hack, J. Hamann, and A. T. Rowshani, "Serine proteases of the human immune system in health and disease," Molecular Immunology, vol. 47, no. 11-12, pp. 1943-1955, 2010.

[2] C. A. Borgoño and E. P. Diamandis, "The emerging roles of human tissue kallikreins in cancer," Nature Reviews Cancer, vol. 4, no. 11, pp. 876-890, 2004.

[3] T. Kryza, M. L. Silva, D. Loessner, N. Heuzé-Vourc'h, and J. A. Clements, "The kallikrein-related peptidase family: dysregulation and functions during cancer progression," Biochimie, 2015.

[4] M. Schmitt, V. Magdolen, F. Yang et al., "Emerging clinical importance of the cancer biomarkers kallikrein-related peptidases (KLK) in female and male reproductive organ malignancies," Radiology and Oncology, vol. 47, no. 4, pp. 319-329, 2013.

[5] Y. Dong, D. Loessner, H. Irving-Rodgers, A. Obermair, J. L. Nicklin, and J. A. Clements, "Metastasis of ovarian cancer is mediated by kallikrein related peptidases," Clinical and Experimental Metastasis, vol. 31, no. 1, pp. 135-147, 2014.

[6] G. M. Yousef, G. M. Yacoub, M.-E. Polymeris, C. Popalis, A. Soosaipillai, and E. P. Diamandis, "Kallikrein gene downregulation in breast cancer," British Journal of Cancer, vol. 90, no. 1, pp. 167-172, 2004.

[7] G. Sotiropoulou, G. Pampalakis, and E. P. Diamandis, "Functional roles of human Kallikrein-related peptidases," Journal of Biological Chemistry, vol. 284, no. 48, pp. 32989-32994, 2009.

[8] M. J. Duffy, "PSA in screening for prostate cancer: more good than harm or more harm than good?" Advances in Clinical Chemistry, vol. 66, pp. 1-23, 2014.

[9] A. Scorilas and K. Mavridis, "Predictions for the future of kallikrein-related peptidases in molecular diagnostics," Expert Review of Molecular Diagnostics, vol. 14, no. 6, pp. 713-722, 2014.

[10] C. López-Otín and J. S. Bond, "Proteases: multifunctional enzymes in life and disease," The Journal of Biological Chemistry, vol. 283, no. 45, pp. 30433-30437, 2008.

[11] X. S. Puente, A. Gutiérrez-Fernández, G. R. Ordóñez, L. W. Hillier, and C. López-Otín, "Comparative genomic analysis of human and chimpanzee proteases," Genomics, vol. 86, no. 6, pp. 638-647, 2005

[12] X. S. Puente, L. M. Sánchez, C. M. Overall, and C. LópezOtín, "Human and mouse proteases: a comparative genomic approach," Nature Reviews Genetics, vol. 4, no. 7, pp. 544-558, 2003.

[13] X. S. Puente and C. López-Otín, "A genomic analysis of rat proteases and protease inhibitors," Genome Research, vol. 14, no. 4, pp. 609-622, 2004.

[14] V. Quesada, G. Velasco, X. S. Puente, W. C. Warren, and C. López-Otín, "Comparative genomic analysis of the zebra finch degradome provides new insights into evolution of proteases in birds and mammals," BMC Genomics, vol. 11, article 220, 2010.

[15] M. Fujinaga, M. M. Cherney, H. Oyama, K. Oda, and M. N. G. James, "The molecular structure and catalytic mechanism of a novel carboxyl peptidase from Scytalidium lignicolum," 
Proceedings of the National Academy of Sciences of the United States of America, vol. 101, no. 10, pp. 3364-3369, 2004.

[16] N. D. Rawlings, D. P. Tolle, and A. J. Barrett, "MEROPS: the peptidase database," Nucleic Acids Research, vol. 32, pp. D160D164, 2004.

[17] J. E. Fuchs, S. von Grafenstein, R. G. Huber, C. Kramer, and K. R. Liedl, "Substrate-driven mapping of the degradome by comparison of sequence logos," PLoS Computational Biology, vol. 9, no. 11, Article ID e1003353, 2013.

[18] N. Bergbold and M. K. Lemberg, "Emerging role of rhomboid family proteins in mammalian biology and disease," Biochimica et Biophysica Acta, vol. 1828, no. 12, pp. 2840-2848, 2013.

[19] N. D. Rawlings, A. J. Barrett, and A. Bateman, "MEROPS: the database of proteolytic enzymes, their substrates and inhibitors," Nucleic Acids Research, vol. 40, no. 1, pp. D343-D350, 2012.

[20] V. Quesada, G. R. Ordóñez, L. M. Sánchez, X. S. Puente, and C. López-Otín, "The degradome database: mammalian proteases and diseases of proteolysis," Nucleic Acids Research, vol. 37, no. 1, pp. D239-D243, 2009.

[21] M. J. Page and E. Di Cera, "Serine peptidases: classification, structure and function," Cellular and Molecular Life Sciences, vol. 65, no. 7-8, pp. 1220-1236, 2008.

[22] E. Di Cera, "Serine proteases," IUBMB Life, vol. 61, no. 5, pp. 510-515, 2009.

[23] S. Saito, K. Murakoshi, S. Kotake, N. Kamatani, and T. Tomatsu, "Granzyme B induces apoptosis of chondrocytes with natural killer cell-like cytotoxicity in rheumatoid arthritis," Journal of Rheumatology, vol. 35, no. 10, pp. 1932-1943, 2008.

[24] C. M. Tschopp, N. Spiegl, S. Didichenko et al., "Granzyme B, a novel mediator of allergic inflammation: its induction and release in blood basophils and human asthma," Blood, vol. 108, no. 7, pp. 2290-2299, 2006.

[25] H. E. Thomas, J. A. Trapani, and T. W. H. Kay, "The role of perforin and granzymes in diabetes," Cell Death and Differentiation, vol. 17, no. 4, pp. 577-585, 2010.

[26] C. M. Chamberlain and D. J. Granville, "The role of Granzyme B in atheromatous diseases," Canadian Journal of Physiology and Pharmacology, vol. 85, no. 1, pp. 89-95, 2007.

[27] D. A. Ngan, S. V. Vickerman, D. J. Granville, S. F. P. Man, and D. D. Sin, "The possible role of granzyme B in the pathogenesis of chronic obstructive pulmonary disease," Therapeutic Advances in Respiratory Disease, vol. 3, no. 3, pp. 113-129, 2009.

[28] Y. Saito, H. Kondo, and Y. Hojo, "Granzyme B as a novel factor involved in cardiovascular diseases," Journal of Cardiology, vol. 57, no. 2, pp. 141-147, 2011.

[29] P. R. Hiebert and D. J. Granville, "Granzyme B in injury, inflammation, and repair," Trends in Molecular Medicine, vol. 18, no. 12, pp. 732-741, 2012.

[30] W. A. Boivin, D. M. Cooper, P. R. Hiebert, and D. J. Granville, "Intracellular versus extracellular granzyme B in immunity and disease: challenging the dogma," Laboratory Investigation, vol. 89, no. 11, pp. 1195-1220, 2009.

[31] E. Darrah and A. Rosen, "Granzyme B cleavage of autoantigens in autoimmunity," Cell Death and Differentiation, vol. 17, no. 4, pp. 624-632, 2010.

[32] A. Hendel, P. R. Hiebert, W. A. Boivin, S. J. Williams, and D. J. Granville, "Granzymes in age-related cardiovascular and pulmonary diseases," Cell Death and Differentiation, vol. 17, no. 4, pp. 596-606, 2010.
[33] A. Roghanian and J.-M. Sallenave, "Neutrophil elastase (NE) and NE inhibitors: canonical and noncanonical functions in lung chronic inflammatory diseases (cystic fibrosis and chronic obstructive pulmonary disease)," Journal of Aerosol Medicine and Pulmonary Drug Delivery, vol. 21, no. 1, pp. 125-144, 2008.

[34] M. L. Fajt and S. E. Wenzel, "Mast cells, their subtypes, and relation to asthma phenotypes," Annals of the American Thoracic Society, vol. 10, supplement, pp. S158-S164, 2013.

[35] M. R. Namazi, "Possible molecular mechanisms to account for the involvement of tryptase in the pathogenesis of psoriasis," Autoimmunity, vol. 38, no. 6, pp. 449-452, 2005.

[36] P. T. Kovanen, "Mast cells and degradation of pericellular and extracellular matrices: potential contributions to erosion, rupture and intraplaque haemorrhage of atherosclerotic plaques," Biochemical Society Transactions, vol. 35, no. 5, pp. 857-861, 2007.

[37] C. Overed-Sayer, L. Rapley, T. Mustelin, and D. L. Clarke, "Are mast cells instrumental for fibrotic diseases?" Frontiers in Pharmacology, vol. 4, article 174, Article ID 00174, 2014.

[38] U. Blank, M. Essig, L. Scandiuzzi, M. Benhamou, and Y. Kanamaru, "Mast cells and inflammatory kidney disease," Immunological Reviews, vol. 217, no. 1, pp. 79-95, 2007.

[39] E. P. Diamandis, A. Scorilas, T. Kishi et al., "Altered kallikrein 7 and 10 concentrations in cerebrospinal fluid of patients with Alzheimer's disease and frontotemporal dementia," Clinical Biochemistry, vol. 37, no. 3, pp. 230-237, 2004.

[40] E. P. Diamandis, G. M. Yousef, C. Petraki, and A. R. Soosaipillai, "Human kallikrein 6 as a biomarker of Alzheimer's disease," Clinical Biochemistry, vol. 33, no. 8, pp. 663-667, 2000.

[41] M. Menendez-Gonzalez, P. Castro-Santos, A. Suarez et al., "Value of measuring plasmatic levels of neurosin in the diagnosis of Alzheimer's disease," Journal of Alzheimer's Disease, vol. 14, no. 1, pp. 59-67, 2008.

[42] E. L. Ashby, P. G. Kehoe, and S. Love, "Kallikrein-related peptidase 6 in Alzheimer's disease and vascular dementia," Brain Research, vol. 1363, pp. 1-10, 2010.

[43] S.-K. Wang, Y. Hu, J. P. Simmer et al., "Novel KLK4 and MMP20 mutations discovered by whole-exome sequencing," Journal of Dental Research, vol. 92, no. 3, pp. 266-271, 2013.

[44] H.-C. Chan, N. M. R. P. Estrella, R. N. Milkovich, J.-W. Kim, J. P. Simmer, and J. C.-C. Hu, "Target gene analyses of 39 amelogenesis imperfecta kindreds," European Journal of Oral Sciences, vol. 119, supplement 1, pp. 311-323, 2011.

[45] S.-K. Lee, F. Seymen, K.-E. Lee et al., "Novel WDR72 mutation and cytoplasmic localization," Journal of Dental Research, vol. 89, no. 12, pp. 1378-1382, 2010.

[46] E. Martínez-Morillo, A. Diamandis, A. D. Romaschin, and E. P. Diamandis, "Kallikrein 6 as a serum prognostic marker in patients with aneurysmal subarachnoid hemorrhage," PLoS ONE, vol. 7, no. 9, Article ID e45676, 2012.

[47] J. Batra, T. O’Mara, R. Patnala, F. Lose, and J. A. Clements, "Genetic polymorphisms in the human tissue kallikrein (KLK) locus and their implication in various malignant and nonmalignant diseases," Biological Chemistry, vol. 393, no. 12, pp. 1365-1390, 2012.

[48] R. A. Myers, B. E. Himes, C. R. Gignoux et al., "Further replication studies of the EVE Consortium meta-analysis identifies 2 asthma risk loci in European Americans," The Journal of Allergy and Clinical Immunology, vol. 130, no. 6, pp. 1294-1301, 2012. 
[49] H. Xie, L. Li, L.-D. Xiong, F. Liao, and G.-R. Zhang, "The changes of skin barrier of patients with different facial dermatitis and the comparison of CE and KLK5," Journal of Sichuan University, vol. 44, no. 6, pp. 940-998, 2013.

[50] P. Fortugno, L. Furio, M. Teson et al., "The 420k LEKTI variant alters LEKTI proteolytic activation and results in protease deregulation: implications for atopic dermatitis," Human Molecular Genetics, vol. 21, no. 19, pp. 4187-4200, 2012.

[51] A. Izumi, Y. Iijima, H. Noguchi et al., "Genetic variations of human neuropsin gene and psychiatric disorders: polymorphism screening and possible association with bipolar disorder and cognitive functions," Neuropsychopharmacology, vol. 33, no. 13, pp. 3237-3245, 2008.

[52] Q. D. Li, F. J. Li, X. C. Liu, and H. Jiang, “Klk1 A1789g gene polymorphism and the risk of coronary artery stenosis in the Chinese population," Genetics and Molecular Research, vol. 12, no. 2, pp. 1636-1645, 2013.

[53] Y.-Y. Yao, C. Fu, G.-S. Ma et al., "Tissue kallikrein is related to the severity of coronary artery disease," Clinica Chimica Acta, vol. 423, pp. 90-98, 2013.

[54] P. Susantitaphong, M. C. Perianayagam, S. W. Kang et al., "Association of functional kallikrein-1 promoter polymorphisms and acute kidney injury: a case-control and longitudinal cohort study," Nephron. Clinical practice, vol. 122, no. 3-4, pp. 107-113, 2012.

[55] K. Liu, Q.-Z. Li, A. M. Delgado-Vega et al., "Kallikrein genes are associated with lupus and glomerular basement membranespecific antibody-induced nephritis in mice and humans," The Journal of Clinical Investigation, vol. 119, no. 4, pp. 911-923, 2009.

[56] W. H. Yiu, D. W. L. Wong, L. Y. Y. Chan et al., "Tissue kallikrein mediates pro-inflammatory pathways and activation of protease-activated receptor-4 in proximal tubular epithelial cells," PLoS ONE, vol. 9, no. 2, Article ID e88894, 2014.

[57] J. E. Burda, M. Radulovic, H. Yoon, and I. A. Scarisbrick, "Critical role for PAR1 in kallikrein 6-mediated oligodendrogliopathy," Glia, vol. 61, no. 9, pp. 1456-1470, 2013.

[58] I. A. Scarisbrick, H. Yoon, M. Panos et al., "Kallikrein 6 regulates early CNS demyelination in a viral model of multiple sclerosis," Brain Pathology, vol. 22, no. 5, pp. 709-722, 2012.

[59] A. L. O. Hebb, V. Bhan, A. D. Wishart, C. S. Moore, and G. S. Robertson, "Human kallikrein 6 cerebrospinal levels are elevated in multiple sclerosis," Current Drug Discovery Technologies, vol. 7, no. 2, pp. 137-140, 2010.

[60] M. Wennström, Y. Surova, S. Hall et al., "Low CSF levels of both $\alpha$-synuclein and the $\alpha$-synuclein cleaving enzyme neurosin in patients with synucleinopathy," PLoS ONE, vol. 8, no. 1, Article ID e53250, 2013.

[61] H. Yoon, M. Radulovic, J. Wu et al., "Kallikrein 6 signals through PAR1 and PAR2 to promote neuron injury and exacerbate glutamate neurotoxicity," Journal of Neurochemistry, vol. 127, no. 2, pp. 283-298, 2013.

[62] M. Radulovic, H. Yoon, N. Larson et al., "Kallikrein cascades in traumatic spinal cord injury: in vitro evidence for roles in axonopathy and neuron degeneration," Journal of Neuropathology and Experimental Neurology, vol. 72, no. 11, pp. 1072-1089, 2013.

[63] I. A. Scarisbrick, M. Radulovic, J. E. Burda et al., "Kallikrein 6 is a novel molecular trigger of reactive astrogliosis," Biological Chemistry, vol. 393, no. 5, pp. 355-367, 2012.

[64] A. V. Rawlings and R. Voegeli, "Stratum corneum proteases and dry skin conditions," Cell and Tissue Research, vol. 351, no. 2, pp. 217-235, 2013.
[65] A. Briot, M. Lacroix, A. Robin, M. Steinhoff, C. Deraison, and A. Hovnanian, "Par2 inactivation inhibits early production of TSLP, but not cutaneous inflammation, in netherton syndrome adult mouse model," The Journal of Investigative Dermatology, vol. 130, no. 12, pp. 2736-2742, 2010.

[66] H. D. de Koning, E. H. van den Bogaard, J. G. M. Bergboer et al., "Expression profile of cornified envelope structural proteins and keratinocyte differentiation-regulating proteins during skin barrier repair," British Journal of Dermatology, vol. 166, no. 6, pp. 1245-1254, 2012.

[67] J. Kanitakis, V. Lora, B. Chouvet, G. Zambruno, M. Haftek, and M. Faure, "Circumscribed palmo-plantar hypokeratosis: a disease of desquamation? Immunohistological study of five cases and literature review," Journal of the European Academy of Dermatology and Venereology, vol. 25, no. 3, pp. 296-301, 2011.

[68] K. Shingaki, S. Matsuzaki, M. Taniguchi et al., "Molecular mechanism of kallikrein-related peptidase 8/neuropsininduced hyperkeratosis in inflamed skin," British Journal of Dermatology, vol. 163, no. 3, pp. 466-475, 2010.

[69] K. Shingaki, M. Taniguchi, S. Kanazawa et al., "NGF-p75 and neuropsin/KLK8 pathways stimulate each other to cause hyperkeratosis and acanthosis in inflamed skin," Journal of Dermatological Science, vol. 67, no. 1, pp. 71-73, 2012.

[70] A. Hovnanian, "Netherton syndrome: skin inflammation and allergy by loss of protease inhibition," Cell and Tissue Research, vol. 351, no. 2, pp. 289-300, 2013.

[71] L. Furio, S. de Veer, M. Jaillet et al., "Transgenic kallikrein 5 mice reproduce major cutaneous and systemic hallmarks of Netherton syndrome," Journal of Experimental Medicine, vol. 211, no. 3, pp. 499-513, 2014.

[72] A. Briot, C. Deraison, M. Lacroix et al., "Kallikrein 5 induces atopic dermatitis-like lesions through PAR2-mediated thymic stromal lymphopoietin expression in Netherton syndrome," Journal of Experimental Medicine, vol. 206, no. 5, pp. 1135-1147, 2009.

[73] K. Yamasaki and R. L. Gallo, "Rosacea as a disease of cathelicidins and skin innate immunity," Journal of Investigative Dermatology Symposium Proceedings, vol. 15, no. 1, pp. 12-15, 2011.

[74] A. Eissa, D. Cretu, A. Soosaipillai et al., "Serum kallikrein8 correlates with skin activity, but not psoriatic arthritis, in patients with psoriatic disease," Clinical Chemistry and Laboratory Medicine, vol. 51, no. 2, pp. 317-325, 2013.

[75] N. Komatsu, K. Saijoh, C. Kuk, F. Shirasaki, K. Takehara, and E. P. Diamandis, "Aberrant human tissue kallikrein levels in the stratum corneum and serum of patients with psoriasis: dependence on phenotype, severity and therapy," British Journal of Dermatology, vol. 156, no. 5, pp. 875-883, 2007.

[76] M. Ximerakis, G. Pampalakis, T. I. Roumeliotis et al., "Resistance of naturally secreted $\alpha$-synuclein to proteolysis," The FASEB Journal, vol. 28, no. 7, pp. 3146-3158, 2014.

[77] J. El Annan, G. Jiang, D. Wang, J. Zhou, G. N. Foulks, and H. Shao, "Elevated immunoglobulin to tissue KLK11 in patients with Sjögren syndrome," Cornea, vol. 32, no. 5, pp. e90-e93, 2013.

[78] M. Avgeris, K. Mavridis, and A. Scorilas, "Kallikrein-related peptidases in prostate, breast, and ovarian cancers: from pathobiology to clinical relevance," Biological Chemistry, vol. 393, no. 5, pp. 301-317, 2012.

[79] M. Kioulafa, L. Kaklamanis, E. Stathopoulos, D. Mavroudis, V. Georgoulias, and E. S. Lianidou, "Kallikrein 10 (KLK10) methylation as a novel prognostic biomarker in early breast cancer," Annals of Oncology, vol. 20, no. 6, pp. 1020-1025, 2009. 
[80] G. Pampalakis, E. Prosnikli, T. Agalioti, A. Vlahou, V. Zoumpourlis, and G. Sotiropoulou, "A tumor-protective role for Human kallikrein-related peptidase 6 in breast cancer mediated by inhibition of epithelial-to-mesenchymal transition," Cancer Research, vol. 69, no. 9, pp. 3779-3787, 2009.

[81] M. Talieri, M. Devetzi, A. Scorilas et al., "Human kallikreinrelated peptidase 12 (KLK12) splice variants expression in breast cancer and their clinical impact," Tumour Biology, vol. 33, no. 4, pp. 1075-1084, 2012.

[82] K. Michaelidou, A. Ardavanis, and A. Scorilas, "Clinical relevance of the deregulated kallikrein-related peptidase 8 mRNA expression in breast cancer: a novel independent indicator of disease-free survival," Breast Cancer Research and Treatment, vol. 152, no. 2, pp. 323-336, 2015.

[83] M. Talieri, M. Devetzi, A. Scorilas et al., "Evaluation of kallikrein-related peptidase 5 expression and its significance for breast cancer patients: association with kallikrein-related peptidase 7 expression," Anticancer Research, vol. 31, no. 9, pp. 3093-3100, 2011.

[84] A. D. Santin, S. Cane', S. Bellone et al., "The serine protease stratum corneum chymotryptic enzyme (kallikrein 7) is highly overexpressed in squamous cervical cancer cells," Gynecologic Oncology, vol. 94, no. 2, pp. 283-288, 2004.

[85] L. Termini, P. C. Maciag, F. A. Soares et al., "Analysis of human kallikrein 7 expression as a potential biomarker in cervical neoplasia," International Journal of Cancer, vol. 127, no. 2, pp. 485-490, 2010.

[86] C. K. Kontos, D. Chantzis, I. N. Papadopoulos, and A. Scorilas, "Kallikrein-related peptidase 4 (KLK4) mRNA predicts shortterm relapse in colorectal adenocarcinoma patients," Cancer Letters, vol. 330, no. 1, pp. 106-112, 2013.

[87] S. Christodoulou, D. K. Alexopoulou, C. K. Kontos, A. Scorilas, and I. N. Papadopoulos, "Kallikrein-related peptidase-6 (KLK6) mRNA expression is an independent prognostic tissue biomarker of poor disease-free and overall survival in colorectal adenocarcinoma," Tumor Biology, vol. 35, no. 5, pp. 4673-4685, 2014.

[88] M. Talieri, K. Mathioudaki, P. Prezas et al., "Clinical significance of kallikrein-related peptidase 7 (KLK7) in colorectal cancer," Thrombosis and Haemostasis, vol. 101, no. 4, pp. 741-747, 2009.

[89] D. K. Alexopoulou, I. N. Papadopoulos, and A. Scorilas, "Clinical significance of kallikrein-related peptidase (KLK10) mRNA expression in colorectal cancer," Clinical Biochemistry, vol. 46, no. 15, pp. 1453-1461, 2013.

[90] B. Feng, W.-B. Xu, M.-H. Zheng et al., "Clinical significance of human kallikrein 10 gene expression in colorectal cancer and gastric cancer," Journal of Gastroenterology and Hepatology, vol. 21, no. 10, pp. 1596-1603, 2006.

[91] W. Huang, J. Zhong, L. Wu et al., "Downregulation and CpG island hypermethylation of NES1/hK10 gene in the pathogenesis of human gastric cancer," Cancer Letters, vol. 251, no. 1, pp. 7885, 2007.

[92] X. Jiao, H.-J. Lu, M.-M. Zhai et al., “Overexpression of kallikrein gene 10 is a biomarker for predicting poor prognosis in gastric cancer," World Journal of Gastroenterology, vol. 19, no. 48, pp. 9425-9431, 2013.

[93] M. Devetzi, T. Trangas, A. Scorilas, D. Xynopoulos, and M. Talieri, "Parallel overexpression and clinical significance of kallikrein-related peptidases 7 and 14 (KLK7KLK14) in colon cancer," Thrombosis and Haemostasis, vol. 109, no. 4, pp. 716725,2013
[94] Y.-G. Wen, Q. Wang, C.-Z. Zhou et al., "Identification and validation of Kallikrein-ralated peptidase 11 as a novel prognostic marker of gastric cancer based on immunohistochemistry," Journal of Surgical Oncology, vol. 104, no. 5, pp. 516-524, 2011.

[95] G. Konstantoudakis, D. Florou, K. Mavridis, I. N. Papadopoulos, and A. Scorilas, "Kallikrein-related peptidase 13 (KLK13) gene expressional status contributes significantly in the prognosis of primary gastric carcinomas," Clinical Biochemistry, vol. 43, no. 15, pp. 1205-1211, 2010.

[96] M. J. Worsham, K. M. Chen, V. Meduri et al., "Epigenetic events of disease progression in head and neck squamous cell carcinoma," Archives of Otolaryngology-Head and Neck Surgery, vol. 132, no. 6, pp. 668-677, 2006.

[97] J. R. Pettus, J. J. Johnson, Z. Shi et al., "Multiple kallikrein (KLK $5,7,8$, and 10) expression in squamous cell carcinoma of the oral cavity," Histology and Histopathology, vol. 24, no. 2, pp. 197-207, 2009.

[98] C.-J. Liu, T.-Y. Liu, L.-T. Kuo et al., "Differential gene expression signature between primary and metastatic head and neck squamous cell carcinoma," The Journal of Pathology, vol. 214, no. 4, pp. 489-497, 2008.

[99] H. Zhao, Y. Dong, J. Quan et al., "Correlation of the expression of human kallikrein-related peptidases 4 and 7 with the prognosis in oral squamous cell carcinoma," Head and Neck, vol. 33, no. 4, pp. 566-572, 2011.

[100] M. Talieri, M. Zoma, M. Devetzi, A. Scorilas, and A. Ardavanis, "Kallikrein-related peptidase 6 (KLK6)gene expression in intracranial tumors," Tumor Biology, vol. 33, no. 5, pp. 13751383, 2012.

[101] P. Prezas, A. Scorilas, C. Yfanti et al., "The role of human tissue kallikreins 7 and 8 in intracranial malignancies," Biological Chemistry, vol. 387, no. 12, pp. 1607-1612, 2006.

[102] C. Planque, L. Li, Y. Zheng et al., "A multiparametric serum kallikrein panel for diagnosis of non-small cell lung carcinoma," Clinical Cancer Research, vol. 14, no. 5, pp. 1355-1362, 2008.

[103] C. Planque, Y.-H. Choi, S. Guyetant, N. Heuzé-Vourc'h, L. Briollais, and Y. Courty, "Alternative splicing variant of kallikreinrelated peptidase 8 as an independent predictor of unfavorable prognosis in lung cancer," Clinical Chemistry, vol. 56, no. 6, pp. 987-997, 2010.

[104] J. Singh, A. Naran, N. L. Misso, P. J. Rigby, P. J. Thompson, and K. D. Bhoola, "Expression of kallikrein-related peptidases (KRP/ $\mathrm{hK} 5,7,6,8)$ in subtypes of human lung carcinoma," International Immunopharmacology, vol. 8, no. 2, pp. 300-306, 2008.

[105] Y.-P. Sher, C.-C. Chou, R.-H. Chou et al., "Human kallikrein 8 protease confers a favorable clinical outcome in non-small cell lung cancer by suppressing tumor cell invasiveness," Cancer Research, vol. 66, no. 24, pp. 11763-11770, 2006.

[106] Y. Zhang, R. Wang, H. Song et al., "Methylation of multiple genes as a candidate biomarker in non-small cell lung cancer," Cancer Letters, vol. 303, no. 1, pp. 21-28, 2011.

[107] S. Krenzer, H. Peterziel, C. Mauch et al., "Expression and function of the kallikrein-related peptidase 6 in the human melanoma microenvironment," Journal of Investigative Dermatology, vol. 131, no. 11, pp. 2281-2288, 2011.

[108] W. K. Martins, G. H. Esteves, O. M. Almeida et al., "Gene network analyses point to the importance of human tissue kallikreins in melanoma progression," BMC Medical Genomics, vol. 4, article 76, 2011.

[109] K. Oikonomopoulou, A. Scorilas, I. P. Michael et al., "Kallikreins as markers of disseminated tumour cells in ovarian 
cancer-a pilot study," Tumor Biology, vol. 27, no. 2, pp. 104-114, 2006.

[110] D. Loessner, V. M. C. Quent, J. Kraemer et al., "Combined expression of KLK4, KLK5, KLK6, and KLK7 by ovarian cancer cells leads to decreased adhesion and paclitaxel-induced chemoresistance," Gynecologic Oncology, vol. 127, no. 3, pp. 569578, 2012.

[111] J. Dorn, N. Harbeck, R. Kates et al., "Impact of expression differences of kallikrein-related peptidases and of uPA and PAI1 between primary tumor and omentum metastasis in advanced ovarian cancer," Annals of Oncology, vol. 22, no. 4, pp. 877-883, 2011.

[112] J. Dorn, V. Magdolen, A. Gkazepis et al., "Circulating biomarker tissue kallikrein-related peptidase KLK5 impacts ovarian cancer patients' survival," Annals of Oncology, vol. 22, no. 8, pp. 17831790, 2011.

[113] E. Bandiera, L. Zanotti, A. S. C. Fabricio et al., "Cancer antigen 125 , human epididymis 4 , kallikrein 6 , osteopontin and soluble mesothelin-related peptide immunocomplexed with immunoglobulin M in epithelial ovarian cancer diagnosis," Clinical Chemistry and Laboratory Medicine, vol. 51, no. 9, pp. 1815-1824, 2013.

[114] S. Sarojini, A. Tamir, H. Lim et al., "Early detection biomarkers for ovarian cancer," Journal of Oncology, vol. 2012, Article ID 709049, 15 pages, 2012.

[115] S. C. L. Koh, K. Razvi, Y. H. Chan et al., "The association with age, human tissue kallikreins 6 and 10 and hemostatic markers for survival outcome from epithelial ovarian cancer," Archives of Gynecology and Obstetrics, vol. 284, no. 1, pp. 183-190, 2011.

[116] C. G. Gunawardana, C. Kuk, C. R. Smith, I. Batruch, A. Soosaipillai, and E. P. Diamandis, "Comprehensive analysis of conditioned media from ovarian cancer cell lines identifies novel candidate markers of epithelial ovarian cancer," Journal of Proteome Research, vol. 8, no. 10, pp. 4705-4713, 2009.

[117] A. Psyrri, P. Kountourakis, A. Scorilas et al., "Human tissue kallikrein 7, a novel biomarker for advanced ovarian carcinoma using a novel in situ quantitative method of protein expression," Annals of Oncology, vol. 19, no. 7, pp. 1271-1277, 2008.

[118] P. Kountourakis, A. Psyrri, A. Scorilas et al., "Expression and prognostic significance of kallikrein-related peptidase 8 protein levels in advanced ovarian cancer by using automated quantitative analysis," Thrombosis and Haemostasis, vol. 101, no. 3, pp. 541-546, 2009.

[119] C. A. Borgoño, T. Kishi, A. Scorilas et al., "Human kallikrein 8 protein is a favorable prognostic marker in ovarian cancer," Clinical Cancer Research, vol. 12, no. 5, pp. 1487-1493, 2006.

[120] G. M. Yousef, L. G. Kyriakopoulou, A. Scorilas et al., "Quantitative expression of the human kallikrein gene 9 (KLK9) in ovarian cancer: a new independent and favorable prognostic marker," Cancer Research, vol. 61, no. 21, pp. 7811-7818, 2001.

[121] J. Batra, O. L. Tan, T. O’Mara et al., "Kallikrein-related peptidase 10 (KLK10) expression and single nucleotide polymorphisms in ovarian cancer survival," International Journal of Gynecological Cancer, vol. 20, no. 4, pp. 529-536, 2010.

[122] C. A. Borgoño, S. Fracchiol, G. M. Yousef et al., "Favorable prognostic value of tissue human kallikrein 11 (hK11) in patients with ovarian carcinoma," International Journal of Cancer, vol. 106, no. 4, pp. 605-610, 2003.

[123] A. Scorilas, C. A. Borgono, N. Harbeck et al., "Human kallikrein 13 protein in ovarian cancer cytosols: a new favorable prognostic marker," Journal of Clinical Oncology, vol. 22, pp. 678-685, 2004.
[124] G. M. Yousef, S. Fracchioli, A. Scorilas et al., "Steroid hormone regulation and prognostic value of the human kallikrein gene 14 in ovarian cancer," American Journal of Clinical Pathology, vol. 119 , no. 3, pp. 346-355, 2003.

[125] J. Batra, C. M. Nagle, T. O’Mara et al., “A Kallikrein 15 (KLK15) single nucleotide polymorphism located close to a novel exon shows evidence of association with poor ovarian cancer survival," BMC Cancer, vol. 11, article 119, 2011.

[126] V. Iakovlev, E. R. Siegel, M.-S. Tsao, and R. S. Haun, "Expression of kallikrein-related peptidase 7 predicts poor prognosis in patients with unresectable pancreatic ductal adenocarcinoma," Cancer Epidemiology Biomarkers and Prevention, vol. 21, no. 7, pp. 1135-1142, 2012.

[127] M. G. Lawrence, J. Lai, and J. A. Clements, "Kallikreins on steroids: structure, function, and hormonal regulation of prostate-specific antigen and the extended kallikrein locus," Endocrine Reviews, vol. 31, no. 4, pp. 407-446, 2010.

[128] T. L. Veveris-Lowe, S. J. Kruger, T. Walsh, R. A. Gardiner, and J. A. Clements, "Seminal fluid characterization for male fertility and prostate cancer: Kallikrein-related serine proteases and whole proteome approaches," Seminars in Thrombosis and Hemostasis, vol. 33, no. 1, pp. 87-99, 2007.

[129] K. J. O’Malley, K. Eisermann, L. E. Pascal et al., "Proteomic analysis of patient tissue reveals PSA protein in the stroma of benign prostatic hyperplasia," Prostate, vol. 74, no. 8, pp. 892900, 2014.

[130] D. L. J. Thorek, M. J. Evans, S. V. Carlsson, D. Ulmert, and H. Lilja, "Prostate-specific kallikrein-related peptidases and their relation to prostate cancer biology and detection," Thrombosis and Haemostasis, vol. 110, no. 3, pp. 484-492, 2013.

[131] Á. Borque, J. del Amo, L. M. Esteban et al., "Genetic predisposition to early recurrence in clinically localized prostate cancer," BJU International, vol. 111, no. 4, pp. 549-558, 2013.

[132] M. Kohli, P. G. Rothberg, C. Feng et al., "Exploratory study of a KLK2 polymorphism as a prognostic marker in prostate cancer," Cancer Biomarkers, vol. 7, no. 2, pp. 101-108, 2010.

[133] R. K. Nam, W. W. Zhang, L. H. Klotz et al., "Variants of the hK2 protein gene (KLK2) are associated with serum hK2 levels and predict the presence of prostate cancer at biopsy," Clinical Cancer Research, vol. 12, no. 21, pp. 6452-6458, 2006.

[134] A. Amaro, A. I. Esposito, A. Gallina et al., "Validation of proposed prostate cancer biomarkers with gene expression data: a long road to travel," Cancer and Metastasis Reviews, vol. 33, no. 2, pp. 657-671, 2014

[135] I. M. Shui, S. Lindström, A. S. Kibel et al., "Prostate cancer (PCa) risk variants and risk of fatal $\mathrm{PCa}$ in the national cancer institute breast and prostate cancer cohort consortium," European Urology, vol. 65, no. 6, pp. 1069-1075, 2014.

[136] A. Soni, A. Bansal, A. K. Mishra et al., "Association of androgen receptor, prostate-specific antigen, and CYP19 gene polymorphisms with prostate carcinoma and benign prostatic hyperplasia in a north Indian population," Genetic Testing and Molecular Biomarkers, vol. 16, no. 8, pp. 835-840, 2012.

[137] E. M. Kwon, S. K. Holt, R. Fu et al., "Androgen metabolism and JAK/STAT pathway genes and prostate cancer risk," Cancer Epidemiology, vol. 36, no. 4, pp. 347-353, 2012.

[138] S. Nobata, A. Hishida, M. Naito et al., "Association between KLK3 rs2735839 G/A polymorphism and serum psa levels in Japanese men," Urologia Internationalis, vol. 89, no. 1, pp. 3944, 2012. 
[139] K. L. Penney, F. R. Schumacher, P. Kraft et al., "Association of KLK3 (PSA) genetic variants with prostate cancer risk and PSA levels," Carcinogenesis, vol. 32, no. 6, pp. 853-859, 2011.

[140] K. Mavridis and A. Scorilas, "Prognostic value and biological role of the kallikrein-related peptidases in human malignancies," Future Oncology, vol. 6, no. 2, pp. 269-285, 2010.

[141] K. Mavridis, K. Stravodimos, and A. Scorilas, "Quantified KLK15 gene expression levels discriminate prostate cancer from benign tumors and constitute a novel independent predictor of disease progression," Prostate, vol. 73, no. 11, pp. 1191-1201, 2013.

[142] F. Lose, S. Srinivasan, T. O’Mara et al., "Genetic association of the KLK4 locus with risk of prostate cancer," PLoS ONE, vol. 7, no. 9, Article ID e44520, 2012.

[143] F. Lose, J. Batra, T. O’Mara et al., “Common variation in Kallikrein genes KLK5, KLK6, KLK12, and KLK13 and risk of prostate cancer and tumor aggressiveness," Urologic Oncology: Seminars and Original Investigations, vol. 31, no. 5, pp. 635-643, 2013.

[144] L. Mo, J. Zhang, J. Shi et al., "Human kallikrein 7 induces epithelial-mesenchymal transition-like changes in prostate carcinoma cells: a role in prostate cancer invasion and progression," Anticancer Research, vol. 30, no. 9, pp. 3413-3420, 2010.

[145] X. Bi, H. He, Y. Ye et al., "Association of TMPRSS2 and KLK11 gene expression levels with clinical progression of human prostate cancer," Medical Oncology, vol. 27, no. 1, pp. 145-151, 2010.

[146] F. Lose, M. G. Lawrence, S. Srinivasan et al., "The kallikrein 14 gene is down-regulated by androgen receptor signalling and harbours genetic variation that is associated with prostate tumour aggressiveness," Biological Chemistry, vol. 393, no. 5, pp. 403-412, 2012.

[147] A. Kaushal, S. A. Myers, Y. Dong et al., "A novel transcript from the KLKP1 gene is androgen regulated, down-regulated during prostate cancer progression and encodes the first non-serine protease identified from the human kallikrein gene locus," Prostate, vol. 68, no. 4, pp. 381-399, 2008.

[148] J. Björkqvist, A. Jämsä, and T. Renné, "Plasma kallikrein: the bradykinin-producing enzyme," Thrombosis and Haemostasis, vol. 110, no. 3, pp. 399-407, 2013.

[149] G. M. Yousef, A. Chang, A. Scorilas, and E. P. Diamandis, "Genomic organization of the human kallikrein gene family on chromosome 19q13.3-q13.4," Biochemical and Biophysical Research Communications, vol. 276, no. 1, pp. 125-133, 2000.

[150] G. M. Yousef and E. P. Diamandis, "An overview of the kallikrein gene families in humans and other species: emerging candidate tumour markers," Clinical Biochemistry, vol. 36, no. 6, pp. 443452, 2003.

[151] G. M. Yousef, C. A. Borgono, I. P. Michael, and E. P. Diamandis, "Cloning of a kallikrein pseudogene," Clinical Biochemistry, vol. 37, no. 11, pp. 961-967, 2004.

[152] J. C.-C. Hu, C. Zhang, X. Sun et al., "Characterization of the mouse and human PRSS17 genes, their relationship to other serine proteases, and the expression of PRSS17 in developing mouse incisors," Gene, vol. 251, no. 1, pp. 1-8, 2000.

[153] A. Pavlopoulou, G. Pampalakis, I. Michalopoulos, and G. Sotiropoulou, "Evolutionary history of tissue kallikreins," PLoS ONE, vol. 5, no. 11, Article ID e13781, 2010.

[154] M. Hasegawa, H. Kishino, and T.-A. Yano, "Dating of the human-ape splitting by a molecular clock of mitochondrial DNA," Journal of Molecular Evolution, vol. 22, no. 2, pp. 160-174, 1985.
[155] V. L. Koumandou and A. Scorilas, "Evolution of the plasma and tissue kallikreins, and their alternative splicing isoforms," PLoS ONE, vol. 8, no. 7, Article ID e68074, 2013.

[156] M. B. Elliott, D. M. Irwin, and E. P. Diamandis, "In silico identification and Bayesian phylogenetic analysis of multiple new mammalian kallikrein gene families," Genomics, vol. 88, no. 5, pp. 591-599, 2006.

[157] Å. Lundwall, "Old genes and new genes: the evolution of the kallikrein locus," Thrombosis and Haemostasis, vol. 110, no. 3, pp. 469-475, 2013.

[158] Y. Luo, P. Kumar, and C. R. Mendelson, "Estrogen-related receptor gamma (ERRgamma) regulates oxygen-dependent expression of voltage-gated potassium $\left(\mathrm{K}^{+}\right)$channels and tissue kallikrein during human trophoblast differentiation," Molecular Endocrinology, vol. 27, no. 6, pp. 940-952, 2013.

[159] D. N. Son, L. Li, H. Katsuyama et al., "Abundant expression of Kallikrein 1 gene in human keratinocytes was mediated by GATA3," Gene, vol. 436, no. 1-2, pp. 121-127, 2009.

[160] M. Zeng, Y. Zhang, I. Bhat, D. E. Wazer, H. Band, and V. Band, "The human kallikrein 10 promoter contains a functional retinoid response element," Biological Chemistry, vol. 387, no. 6, pp. 741-747, 2006.

[161] T. Shin, H. Sumiyoshi, N. Matsuo et al., "Sp1 and Sp3 transcription factors upregulate the proximal promoter of the human prostate-specific antigen gene in prostate cancer cells," Archives of Biochemistry and Biophysics, vol. 435, no. 2, pp. 291-302, 2005.

[162] K. Eisermann, S. Tandon, A. Bazarov, A. Brett, G. Fraizer, and H. Piontkivska, "Evolutionary conservation of zinc finger transcription factor binding sites in promoters of genes coexpressed with WT1 in prostate cancer," BMC Genomics, vol. 9, article 337, 2008.

[163] K.-H. Tsui, P.-L. Chang, H.-T. Lin, and H.-H. Juang, "Downregulation of the prostate specific antigen promoter by $\mathrm{p} 53$ in human prostate cancer cells," Journal of Urology, vol. 172, no. 5 I, pp. 2035-2039, 2004.

[164] B. Cinar, F. Yeung, H. Konaka et al., "Identification of a negative regulatory cis-element in the enhancer core region of the prostate-specific antigen promoter: implications for intersection of androgen receptor and nuclear factor $-\kappa \mathrm{B}$ signalling in prostate cancer cells," Biochemical Journal, vol. 379, no. 2, pp. 421-431, 2004.

[165] C. A. Borgoño, I. P. Michael, and E. P. Diamandis, "Human tissue kallikreins: physiologic roles and applications in cancer," Molecular Cancer Research, vol. 2, no. 5, pp. 257-280, 2004.

[166] M. D. Pasic, E. Olkhov, B. Bapat, and G. M. Yousef, "Epigenetic regulation of kallikrein-related peptidases: there is a whole new world out there," Biological Chemistry, vol. 393, no. 5, pp. 319330, 2012.

[167] J. Roman-Gomez, A. Jimenez-Velasco, X. Agirre et al., "The normal epithelial cell-specific 1 (NES1) gene, a candidate tumor suppressor gene on chromosome 19q13.3-4, is downregulated by hypermethylation in acute lymphoblastic leukemia," Leukemia, vol. 18, no. 2, pp. 362-365, 2004.

[168] B. Li, J. Goyal, S. Dhar et al., "CpG methylation as a basis for breast tumor-specific loss of NES1/kallikrein 10 expression," Cancer Research, vol. 61, no. 21, pp. 8014-8021, 2001.

[169] E. Olkhov-Mitsel, T. Van der Kwast, K. J. Kron et al., "Quantitative DNA methylation analysis of genes coding for kallikreinrelated peptidases 6 and 10 as biomarkers for prostate cancer," Epigenetics, vol. 7, no. 9, pp. 1037-1045, 2012.

[170] B. Bharaj, A. Scorilas, E. P. Diamandis et al., "Breast cancer prognostic significance of a single nucleotide polymorphism in 
the proximal androgen response element of the prostate specific antigen gene promoter," Breast Cancer Research and Treatment, vol. 61, no. 2, pp. 111-119, 2000.

[171] Q. Song, J. Chao, and L. Chao, "DNA polymorphisms in the $5^{\prime}$-flanking region of the human tissue kallikrein gene," Human Genetics, vol. 99, no. 6, pp. 727-734, 1997.

[172] L. Kurlender, C. Borgono, I. P. Michael et al., "A survey of alternative transcripts of human tissue kallikrein genes," Biochimica et Biophysica Acta-Reviews on Cancer, vol. 1755, no. 1, pp. 1-14, 2005.

[173] B. W. Matthews, P. B. Sigler, R. Henderson, and D. M. Blow, "Three-dimensional structure of tosyl- $\alpha$-chymotrypsin," Nature, vol. 214, no. 5089, pp. 652-656, 1967.

[174] A. M. Lesk and W. D. Fordham, "Conservation and variability in the structures of serine proteinases of the chymotrypsin family," Journal of Molecular Biology, vol. 258, no. 3, pp. 501-537, 1996.

[175] J. Chao, B. Shen, L. Gao, C.-F. Xia, G. Bledsoe, and L. Chao, "Tissue kallikrein in cardiovascular, cerebrovascular and renal diseases and skin wound healing," Biological Chemistry, vol. 391, no. 4, pp. 345-355, 2010.

[176] C. Ponticelli and P. L. Meroni, "Kallikreins and lupus nephritis," The Journal of Clinical Investigation, vol. 119, no. 4, pp. 768-771, 2009.

[177] E. P. Diamandis, G. M. Yousef, L.-Y. Luo, A. Magklara, and C. V. Obiezu, "The new human kallikrein gene family: implications in carcinogenesis," Trends in Endocrinology and Metabolism, vol. 11, no. 2, pp. 54-60, 2000.

[178] J. L. V. Shaw and E. P. Diamandis, "Distribution of 15 human kallikreins in tissues and biological fluids," Clinical Chemistry, vol. 53, no. 8, pp. 1423-1432, 2007.

[179] N. Komatsu, B. Tsai, M. Sidiropoulos et al., "Quantification of eight tissue kallikreins in the stratum corneum and sweat," The Journal of Investigative Dermatology, vol. 126, no. 4, pp. 925-929, 2006.

[180] B. A. Laflamme and M. F. Wolfner, "Identification and function of proteolysis regulators in seminal fluid," Molecular Reproduction and Development, vol. 80, no. 2, pp. 80-101, 2013.

[181] H. Yoon, S. I. Blaber, W. Li, I. A. Scarisbrick, and M. Blaber, "Activation profiles of human kallikrein-related peptidases by matrix metalloproteinases," Biological Chemistry, vol. 394, no. 1, pp. 137-147, 2013.

[182] A. Serrano-Pozo, M. P. Frosch, E. Masliah, and B. T. Hyman, "Neuropathological alterations in Alzheimer disease," Cold Spring Harbor perspectives in medicine, vol. 1, no. 1, Article ID a006189, 2011.

[183] M. Goedert, "NEURODEGENERATION. Alzheimer's and Parkinson's diseases: the prion concept in relation to assembled A $\beta$, tau, and $\alpha$-synuclein," Science, vol. 349 , no. 6248, Article ID 1255555, 2015.

[184] S. Mitsui, A. Okui, H. Uemura et al., "Decreased cerebrospinal fluid levels of neurosin (KLK6), an aging-related protease, as a possible new risk factor for Alzheimer's disease," Annals of the New York Academy of Sciences, vol. 977, pp. 216-223, 2002.

[185] M. Zarghooni, A. Soosaipillai, L. Grass, A. Scorilas, N. Mirazimi, and E. P. Diamandis, "Decreased concentration of human kallikrein 6 in brain extracts of Alzheimer's disease patients," Clinical Biochemistry, vol. 35, no. 3, pp. 225-231, 2002.

[186] T. D. Shropshire, J. Reifert, S. Rajagopalan, D. Baker, S. C. Feinstein, and P. S. Daugherty, "Amyloid $\beta$ peptide cleavage by kallikrein 7 attenuates fibril growth and rescues neurons from A $\beta$-mediated toxicity in vitro," Biological Chemistry, vol. 395, no. 1, pp. 109-118, 2014.
[187] J. Bayani and E. P. Diamandis, "The physiology and pathobiology of human kallikrein-related peptidase 6 (KLK6)," Clinical Chemistry and Laboratory Medicine, vol. 50, no. 2, pp. 211-233, 2012.

[188] E. Emmanouilidou, K. Melachroinou, T. Roumeliotis et al., "Cell-produced $\alpha$-synuclein is secreted in a calcium-dependent manner by exosomes and impacts neuronal survival," The Journal of Neuroscience, vol. 30, no. 20, pp. 6838-6851, 2010.

[189] C. Kim, D.-H. Ho, J.-E. Suk et al., "Neuron-released oligomeric $\alpha$-synuclein is an endogenous agonist of TLR2 for paracrine activation of microglia," Nature Communications, vol. 4, article 1562, 2013.

[190] H. Tatebe, Y. Watanabe, T. Kasai et al., "Extracellular neurosin degrades alpha-synuclein in cultured cells," Neuroscience Research, vol. 67, no. 4, pp. 341-346, 2010.

[191] T. Kasai, T. Tokuda, N. Yamaguchi et al., "Cleavage of normal and pathological forms of $\alpha$-synuclein by neurosin in vitro," Neuroscience Letters, vol. 436, no. 1, pp. 52-56, 2008.

[192] I. A. Scarisbrick, R. Linbo, A. G. Vandell et al., "Kallikreins are associated with secondary progressive multiple sclerosis and promote neurodegeneration," Biological Chemistry, vol. 389, no. 6, pp. 739-745, 2008.

[193] G. Naffah-Mazzacoratti Mda, T. L. Gouveia, P. S. Simoes, and S. R. Perosa, "What have we learned about the kallikrein-kinin and renin-angiotensin systems in neurological disorders?" World Journal of Biological Chemistry, vol. 5, pp. 130-140, 2014.

[194] Z. Lu, Q. Yang, M. Cui et al., "Tissue kallikrein induces SHSY5Y cell proliferation via epidermal growth factor receptor and extracellular signal-regulated kinase1/2 pathway," Biochemical and Biophysical Research Communications, vol. 446, no. 1, pp. 25-29, 2014.

[195] Y. Jin, S. Qu, M. Tesikova et al., "Molecular circuit involving KLK4 integrates androgen and mTOR signaling in prostate cancer," Proceedings of the National Academy of Sciences of the United States of America, vol. 110, no. 28, pp. E2572-E2581, 2013.

[196] O. A. Stone, C. Richer, C. Emanueli et al., "Critical role of tissue kallikrein in vessel formation and maturation: implications for therapeutic revascularization," Arteriosclerosis, Thrombosis, and Vascular Biology, vol. 29, no. 5, pp. 657-664, 2009.

[197] P. Dominek, P. Campagnolo, M. H-Zadeh et al., "Role of human tissue kallikrein in gastrointestinal stromal tumour invasion," British Journal of Cancer, vol. 103, no. 9, pp. 1422-1431, 2010.

[198] G. Spinetti, O. Fortunato, D. Cordella et al., "Tissue Kallikrein is essential for invasive capacity of circulating proangiogenic cells," Circulation Research, vol. 108, no. 3, pp. 284-293, 2011.

[199] T. Kryza, C. Achard, C. Parent et al., "Angiogenesis stimulated by human kallikrein-related peptidase 12 acting via a plateletderived growth factor B-dependent paracrine pathway," The FASEB Journal, vol. 28, no. 2, pp. 740-751, 2014.

[200] F. Hirschhaeuser, U. G. A. Sattler, and W. Mueller-Klieser, "Lactate: a metabolic key player in cancer," Cancer Research, vol. 71, no. 22, pp. 6921-6925, 2011.

[201] R. Jiang, Z. Shi, J. J. Johnson, Y. Liu, and M. S. Stack, "Kallikrein5 promotes cleavage of desmoglein-1 and loss of cell-cell cohesion in oral squamous cell carcinoma," The Journal of Biological Chemistry, vol. 286, no. 11, pp. 9127-9135, 2011.

[202] T. L. Veveris-Lowe, M. G. Lawrence, R. L. Collard et al., "Kallikrein $4(\mathrm{hK} 4)$ and prostate-specific antigen (PSA) are associated with the loss of E-cadherin and an epithelialmesenchymal transition (EMT)-like effect in prostate cancer cells," Endocrine-Related Cancer, vol. 12, no. 3, pp. 631-643, 2005. 
[203] I. Prassas, A. Eissa, G. Poda, and E. P. Diamandis, "Unleashing the therapeutic potential of human kallikrein-related serine proteases," Nature Reviews Drug Discovery, vol. 14, no. 3, pp. 183-202, 2015.

[204] G. Sotiropoulou and G. Pampalakis, "Targeting the kallikreinrelated peptidases for drug development," Trends in Pharmacological Sciences, vol. 33, no. 12, pp. 623-634, 2012.

[205] K. Tamura, D. Peterson, N. Peterson, G. Stecher, M. Nei, and S. Kumar, "MEGA5: molecular evolutionary genetics analysis using maximum likelihood, evolutionary distance, and maximum parsimony methods," Molecular Biology and Evolution, vol. 28, no. 10, pp. 2731-2739, 2011.

[206] J. Felsenstein, "Confidence limits on phytogenies: an approach using the bootstrap," Evolution, vol. 39, no. 4, pp. 783-791, 1985. 


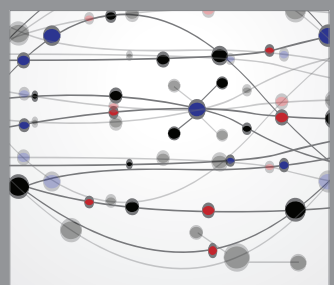

The Scientific World Journal
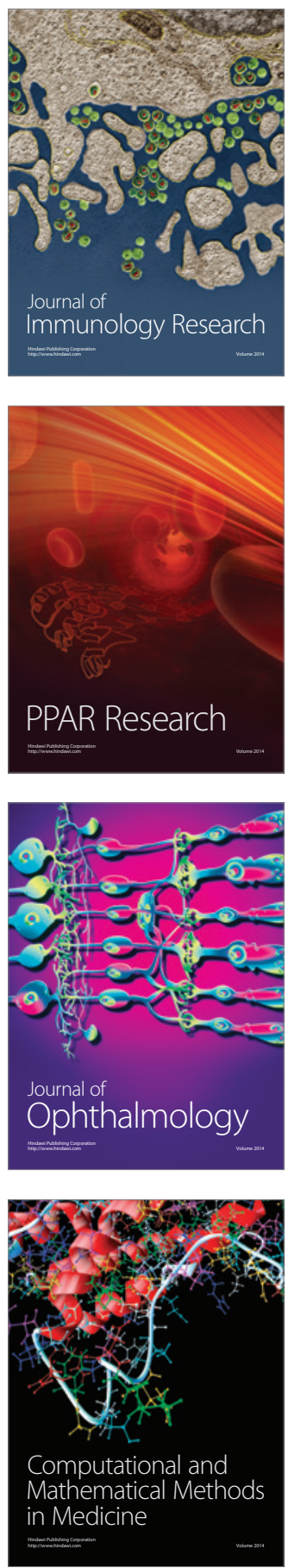

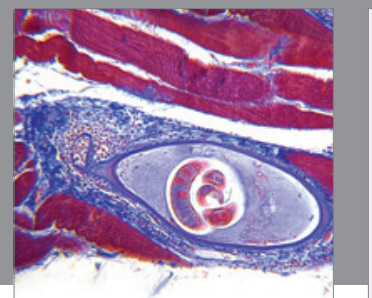

Gastroenterology

Research and Practice
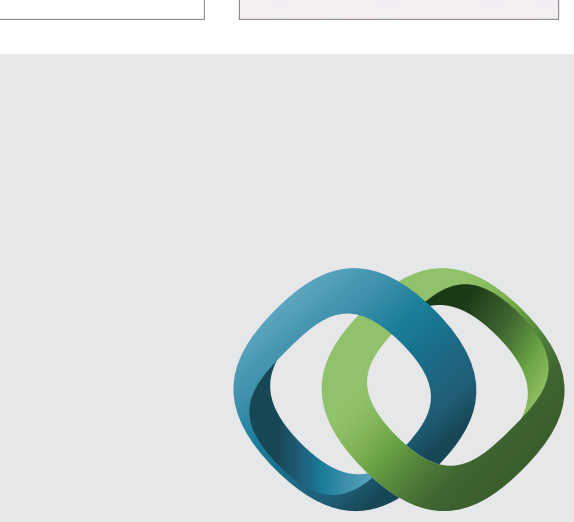

\section{Hindawi}

Submit your manuscripts at

http://www.hindawi.com
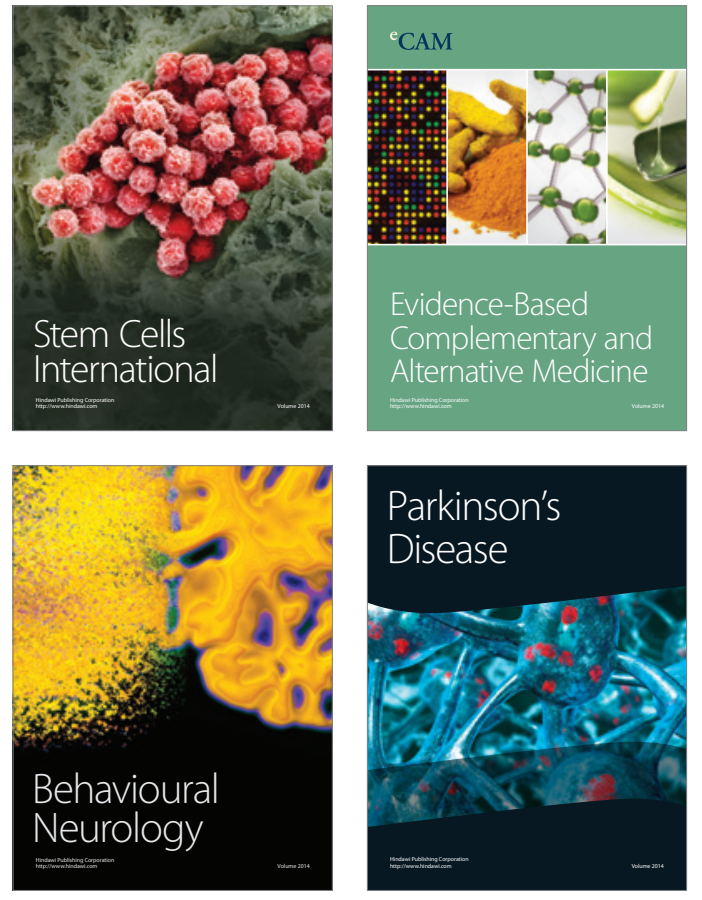
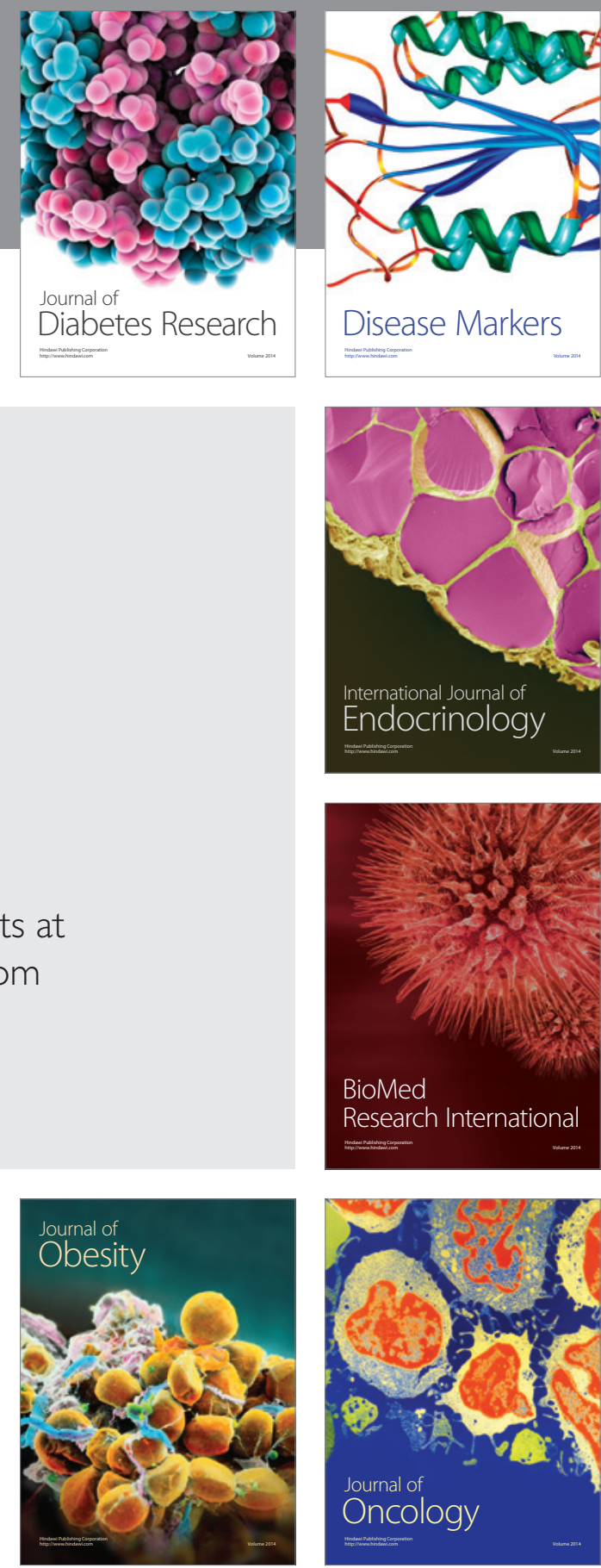

Disease Markers
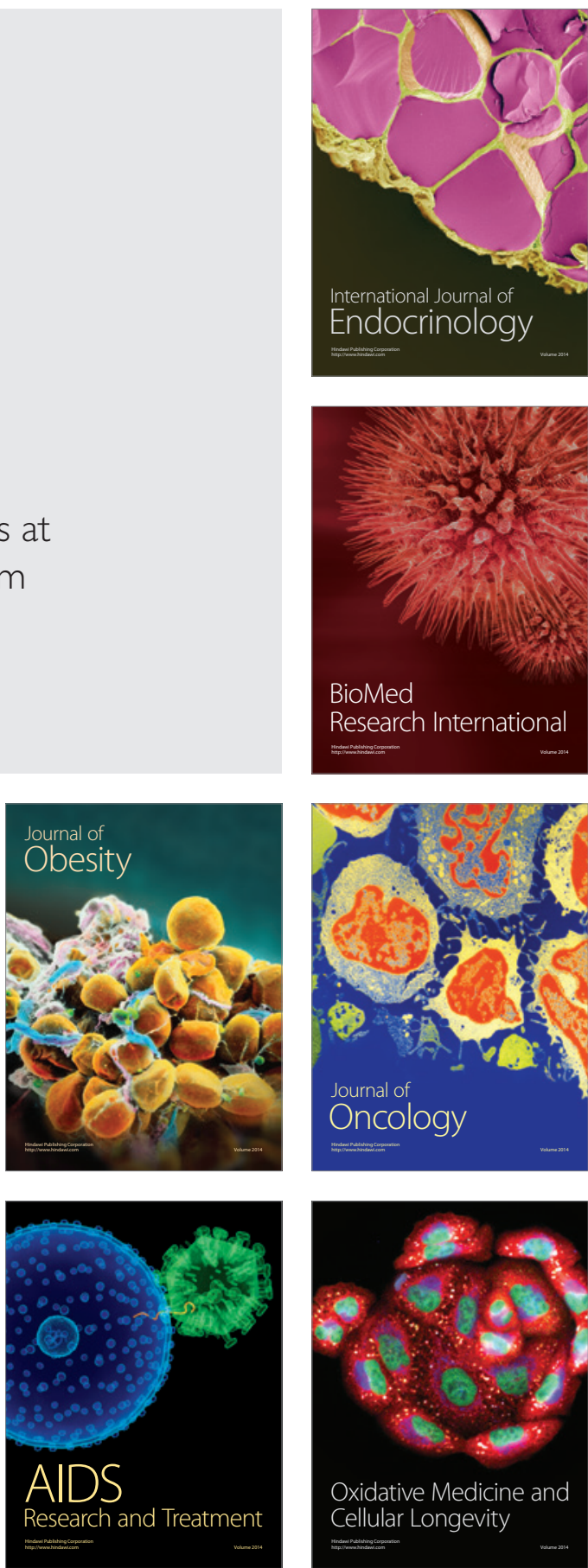